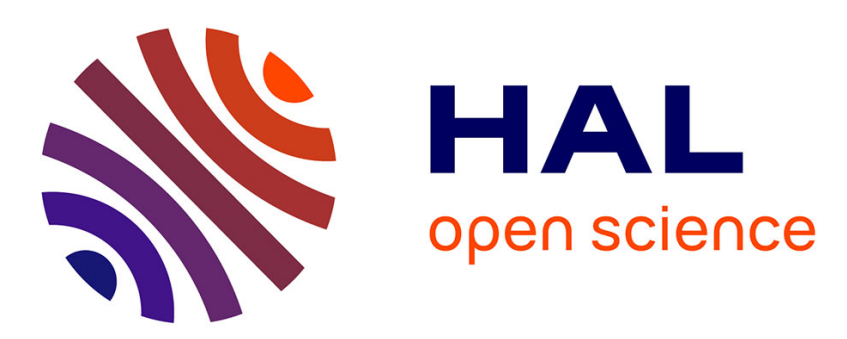

\title{
Time-varying global financial market inefficiency: an instance of pre-, during, and post-subprime crisis
}

Rahul Roy, Shijin Santhakumar

\section{To cite this version:}

Rahul Roy, Shijin Santhakumar. Time-varying global financial market inefficiency: an instance of pre-, during, and post-subprime crisis. DECISION, 2014, 41 (4), pp.449-488. 10.1007/s40622-014-0061-1 . hal-01660506

\section{HAL Id: hal-01660506 https://hal.science/hal-01660506}

Submitted on 11 Dec 2017

HAL is a multi-disciplinary open access archive for the deposit and dissemination of scientific research documents, whether they are published or not. The documents may come from teaching and research institutions in France or abroad, or from public or private research centers.
L'archive ouverte pluridisciplinaire HAL, est destinée au dépôt et à la diffusion de documents scientifiques de niveau recherche, publiés ou non, émanant des établissements d'enseignement et de recherche français ou étrangers, des laboratoires publics ou privés. 


\title{
RESEARCH PAPER
}

\section{Time-varying global financial market inefficiency: an instance of pre-, during, and post-subprime crisis}

\author{
Rahul Roy • Santhakumar Shijin
}

\begin{abstract}
The informational efficiency is the central backdrop among researchers in the quest of behavioral finance since Fama (J Financ 25:383-417, 1970). The succession of time has witnessed the dramatic transformation in the field of global stock markets over the years, and subsequently the liberalizationprivatization-globalization played the role of catalyst to form the global stock market convergence. Predominantly, the financial liberalization in the foreign policies over the last two decades enabled the institutional and rational investors to diversify their risk through holding different classes of asset, forming the portfolio. However, the availability of investment opportunity sets to investor in two stock markets subsequently results in portfolio diversification, and hence arbitrage occurs simultaneously across the two markets (Ito et al., Appl Financ 46(23):2744-2754, 2014). The country risk premium and world risk premium in segmented market and integrated market concurrently vary, and thus it is perceivable to examine the joint efficiency among the various stock markets when markets are highly integrated. This study aims to analyze the time-varying structure of world market dynamic linkages and the persistence of global financial market inefficiency present during an instance of subprime crisis.
\end{abstract}

Keywords Time-varying VAR model ARCH GARCH Subprime crisis Time-varying global financial market inefficiency Market dynamics

JEL Classification C32; C51; G14; F15

R. Roy ( $\square)$, S. Shijin

Department of Commerce, School of Management,

Pondicherry University, Pondicherry - 605014, India

e-mail: rahulroy819@gmail.com

Santhakumar Shijin

e-mail: shijin.s@gmail.com

\section{Introduction}

Efficient market hypothesis (EMH) has been under constant debate, since the conception of fair game in financial economics as proposed by Samuelson (1965). According to Fama (1970), prior studies conducted by Alexander (1961), Cootner (1962) and Godfrey et al. (1964) supported and accounted for the EMH. Moreover, the anomalies reported in Fama's seminal paper (1970) have forced Fama (1991) to alter his own opinion. The intensity and magnitude, which EMH comprised, made it evident that it could never be concluded in a short span. The advocates of behavioral finance, Thaler (2000), Colisk (1996), Fama (1998), and Rubinstein (2001), have added to this debate. The validation of EMH through the conventional theory testing is futile, and thus, it is prolific to set up a measure of degree of relative market inefficiency as in Campbell et al. (1997). Although the enormous amount of literature on market efficiency exists, there is limited literature to facilitate studies pertaining to relative market inefficiency, which implies the existence of exploitable opportunities. According to Ito and Sugiyama (2009), one can never predict the returns of an asset by analyzing past data, if certain level of sequential correlation infers the predictability. This may not imply inefficiency if the predictability is insufficient to overcome transaction costs. The delayed trading of some stocks after a shock may convey inaccurate autocorrelation to an index. Hence, monthly observations of autocorrelation of stock returns posit as a good proxy for testing the market inefficiency (Ito and Sugiyama 2009).

The assumptions of the EMH encompass the generally accepted theory of random walk that market is required to be fully efficient. Cutler et al. (1990) and Shleifer (2000) opine that in reality the financial markets are neither absolutely competent nor entirely inefficient. The markets are competent to a definite 
point; however, some are more so than the others. Further, conversant arbitrageur can surpass lessconversant ones. The diverse features of financial instruments, arbitrageurs and forms of traders are capable to influence the level of the market efficiency (Lee 2000). However, foreign exchange markets and government bond markets are measured to be exceptionally efficient since trading is basically performed by specialized traders (Saxena et al. 2008). In contrast, markets within small capitalization stocks are measured to be less competent than markets within large ones. Evans (2006) revealed in his study that the definition of efficiency is based on the assumptions of weak-form informational efficiency as in Fama (1965, 1970). The peculiar characteristics of completely competent market will include absolute randomness and unpredictable price changes. Therefore, the EMH and random walk hypothesis (RWH) turn out to be closely related. As posited by Evans (2006), the affirmation of random walk is believed to be a sufficient form of the market efficiency; still, the recognition of a random walk does not automatically imply market efficiency. In any form of market, the completely efficient markets are rare in existence (Grossman and Stiglitz 1980); in turn, the market inefficiency being further measured in terms of magnitude is termed as relative market efficiency (Campbell et al. 1997). The measurement of degree of relative market inefficiency will convey the persistence of the market competence in real terms.

The recent global financial crisis which originated from the US subprime mortgage market has spread over to the entire world as a contagion. The impact of such crisis was analyzed by Mishra et al. (2010) through the key market parameters such as market size market liquidity, market turnover ratio, market volatility and market efficiency of Indian capital market. Simultaneously, findings with the appropriate evidence suggest a greater volatility and subsequent persistence of weak form inefficiency of the market. Ito and Sugiyama (2009) in their study used the moving window method in line with Lo (2004) to examine the autocorrelation of stock returns, by incorporating the technique of Kalman smoothing. Seminal study of Wolff (2000) reveals that using Kalman Filter technique for forecasting the future returns is vague. Further, it is unable to outperform the simple random walk forecasting rule in a prediction and hence, it was concluded a mediocre model. In contrast with the above study, the methodology used for examining the time-varying market inefficiency by Ito and Sugiyama (2009) simultaneously ripens the uncertainty over its findings. Hence, it is worthy to create a model which can be better in its accuracy and precision in terms of forecasting the future returns using past information.

\section{Literature review}

The advocates of EMH with subsequent evidences support that the markets are weak-form efficient in information (Alexander (1961), Fama and Blume (1966), Jensen and Benington (1970)). However, studies of Neely (2003) and Doran et al. (2010), which are against the assumptions of EMH which, in turn, accounted for the market inefficiency, further suggest that with the presence of diverse cadre of investors, the market is predictable. Lo (2005) and Ito and Sugiyama (2009) argue and propose a fresh ideology of timevarying market inefficiency. Thus, in line with Lo (2004, 2005), Ramirez et al. (2011) stress over the market efficiency by explaining that effi-ciency varies not only through time but also across the time. Ramirez et al. (2011) used the patterns in the price changes for measuring the market efficiency over the period of 110 years. Consequently, the methodology used in the study has been dated in line with autoregressive models. It suggests that the US stock market was the most efficient around the year 1990 in the last half of century in terms of level of market efficiency. Hence, studies on market efficiency reveal that EMH assumptions are in fact trivial owing to time factor (Bariviera et al. 2012; Kim et al. 2011; Chuluun et al. 2011; Gu and Finnerty 2002; Lagoarde-Segot 2009). However, Akbas et al. (2014) found that market is efficient during the study period, not in absolute terms, rather in terms of time-varying relative market efficiency.

Apart from the existing abundant evidences documenting and validating the persistence of timevarying relative market inefficiency in relation with the emerging and developed economies, the evidences from global market perspective further replicate the persistence of time-varying relative market inefficiency. Influential study of Cristina et al. (2012) documents that the insurance market inefficiency of Central Eastern European countries varies through 
time. In addition, Lim (2008) investigates the relative market efficiency of stock market returns using rolling bi-correlation test statistic approach and finds the evidences for the persistence of relative market inefficiency during crisis period for all economic sectors with the exception of tin and mining. Lim et al. (2007) investigates the effects of 1997 financial crisis on the persistence of efficiency of eight Asian stock markets for the three subsample periods of pre-crisis, during crisis and post-crisis. The findings confirm the persistence of relatively high market inefficiency during the crisis period. Tella et al. (2011) investigate the relationship between global economic crisis and stock market efficiency in African countries, and, hence conclude that except for Johannesburg stock market, the rest of the major stock markets of the African countries are found inefficient and are affected through the contagious effect of global economic crisis. Todea and Lazar (2012) examine the effects of Global crisis on the persistence of relative efficiencies of ten CEE stock markets and find that the degree of relative market inefficiency varies over time. However, the findings of Dunis and Morrison (2007) reveal the vagueness created with regard to the forecasting ability when using Kalmans filter methodology in terms of its accuracy.

Though the gradual market efficiency is the function of spill-over mechanism, the resultant bubble burst shock in global stock market has extensively been examined. Eun and Shim (1989) has used vector autoregressive model to examine the interdependence structure of major stock markets and emphasized that innovations in US stock market spill over to the rest of the stock markets in a quick succession. However, no single global stock market is able to explain the movements in US stock market. The seminal study of Mathur and Subrahmanyam (1990) claimed that US stock market affects the Danish stock market but not the rest of the Nordic stock markets. Consequently, Tsutsui and Hirayama (2004) has used the VAR specification exclusively lag length criteria to capture the responses of stock markets utmost precisely.

Cheung et al. (2009) examined the contagious effect of credit risk mimicking global financial crisis in 2007-2009. Successively Hirayama and Tsutsui (2013) unlock the stock price comovement through systematic and idiosyncratic shocks, respectively. Choudhry and Jayasekera (2013) examines the information asymmetry-try effects on the time-varying beta of firms in UK during the periods of peak and trough by applying bivariate BEKK (Engle and Kroner 1995) GARCH model and subsequently opines the market efficiency is declining from the pre-crisis to crisis periods providing ample evidence of the asymmetric effect of the financial crisis. Ito et al. (2014) has develop a time-varying VAR model to estimate the global market linkages and joint market efficiency while subsequently their behavior depicts convergence of the historical events of global financial system. Ito et al. (2014) argues that the global stock markets are found inefficient in 1980s and European stock markets are jointly inefficient although the respective segmented stock markets are revealing efficiency.

In this conjecture there exist minimum empirical evidences to portray the world market convergence and the time-varying global market inefficiency in weak- form (Fama 1970). The literature on global market efficiency proposes that the market efficiency in absolute terms is rare to exist (Grossman and Stiglitz 1980), and hence relative market efficiency accommodate the persistence of timevarying global market inefficiency being proclaimed as the justification for EMH. The literature on global market linkages implies that the global investors possess the opportunity set to invest in stocks of segmented market as well as global market with a virtue to diversify the risk originated from variations in country risk premium and world risk premium. With the assumption of rational investors holding the diversified portfolio, the present study tends to examine the global market linkages and persistence of time-varying global market inefficiency. To concretize empirically the persistence of time-varying global market inefficiency, the financial global market crisis of 2007-2010 (Choudhry and Jayasekera 2013) as historical event has been incorporated in line with Ito et al. (2012). In addition, the present study tries to contribute in the existing literature of world market linkages through incorporating the effect of information asymmetry on the time-varying beta of an individual stock market while examining the stock market linkages over and across the time phenomenon during the periods of peak and troughs.

\section{Methodology}


The empirical evidences of world market linkages justifies that the rational investors holding the diversified portfolio with a virtue to minimize the risk in returns due to the variations in world and country specific risk premiums, respectively. Hence, the present study tries to examine the linkages among the respective stock markets representing from Americas, Europe, Middle East, Asia/Pacific and Africa. Subsequently, the VAR model has used to set up the framework to examine empirical evidences for global market convergence. Though VAR model can justify the world market linkages through the transmission of information among the stock markets, it is also an important source through which arbitrage opportunities may arise and hence rational investors exploit those set of opportunities to maximize the returns. In this set up Granger-causality test has been used to testify the spill over effect of information from one stock market to another, and hence to infer the process of price formation and discovery. Further, the time duration plays a crucial role to incorporate the new set of information completely into the stock price so as to set the pricing equilibrium. In addition, Impulse response and variance decomposition function is also estimated to examine the short-horizon movements and variations of stock returns among the stock indices individually and collectively.

The time-varying global market inefficiency has been examined, which prevailed during the subprime crisis and which has spread across countries as a contagion and an influential historical event, in order to infer the objectivity of inefficiency during the period of the study. The behavior of the movements in variations of the respective stock markets and its interdependence among the different phases of time duration is an impeccable set up to infer the gradual movements in stock markets and co-movements among the stock markets. To examine the persistence of time-varying global market inefficiency an ARCH and GARCH methodology has been employed. The innovations in the form of shocks to the respective linear regression model allow the predictions to vary over the period of time and us to infer the invariability in the beta coefficient for the respective state variables in the form of stock indices. The methodology and its specifications used in the study are discussed below.

\section{Vector-auto regressive (VAR) model}

The vector autoregression system may written as

$\Gamma(\boldsymbol{L}) \boldsymbol{y}_{t}=\mu+\varepsilon_{t}$

where $\Gamma(\boldsymbol{L})$ is a matrix polynomials in the lag operator, $\varepsilon_{\mathrm{t}}$ is a vector of non-autocorrelated disturbances with zero means and contemporaneous covariance matrix $\boldsymbol{E}\left[\varepsilon_{t} \varepsilon_{t}^{\prime}\right]=\Omega$. The individual equations are

$$
\begin{aligned}
\boldsymbol{y}_{\boldsymbol{m} t}= & \mu_{m}+\sum_{j=1}^{p}\left(\Gamma_{j}\right) \boldsymbol{m}_{1} \boldsymbol{y}_{1, t-t}+\sum_{j=1}^{p}\left(\Gamma_{j}\right) \boldsymbol{m}_{2} \boldsymbol{y}_{2, t-j}+\cdots \\
& +\sum_{j=1}^{p}\left(\Gamma_{j}\right) \boldsymbol{m}_{M} \boldsymbol{y}_{M, t-j}+\varepsilon_{m t}
\end{aligned}
$$

where $\left(\Gamma_{j}\right)_{l m}$ indicated the $(l, m)$ element of $\Gamma_{j}$.

For simplicity, the $p$ th order VAR can be written as first-order VAR as follows:

$$
\begin{aligned}
& \left(\begin{array}{c}
y_{t} \\
y_{t-1} \\
\cdots \\
y_{t-p+1}
\end{array}\right)=\left(\begin{array}{c}
\mu \\
0 \\
\cdots \\
0
\end{array}\right) \\
& +\left[\begin{array}{cccc}
\Gamma_{1} & \Gamma_{2} & \cdots & \Gamma_{p} \\
\mathrm{I} & 0 & \cdots & 0 \\
\cdots & \cdots & \cdots & 0 \\
0 & \cdots & \mathrm{I} & 0
\end{array}\right]\left(\begin{array}{c}
y_{t-1} \\
y_{t-2} \\
\cdots \\
y_{t-p}
\end{array}\right) \\
& +\left(\begin{array}{c}
\varepsilon_{t} \\
0 \\
\cdots \\
0
\end{array}\right)
\end{aligned}
$$

This means generality is intact in casting the treatment in the terms of a first-order model.

$$
\boldsymbol{y}_{t}=\mu+\Gamma \boldsymbol{y}_{t-1}+\varepsilon_{t}
$$

The present study employed VAR model to analyze the inter-relationships among various indices: SPX Index, CCMP Index, SX5E Index, UKX Index, NKY Index, HSI Index, NSE CNX 500 index, TA-100 Index, FTSE Top 40 index and MXZA index. This is the conventional form of the model as originally 
proposed by Sims (1980), which can subsequently be reduced as the form of simultaneous equations model; the corresponding framework is given by

$\Theta y_{t}=\alpha+\Psi_{k} y_{t-k}+\omega_{t}$

where $\Theta$ is a non-singular matrix, and $\boldsymbol{V A R}[\omega]=\sum, \boldsymbol{y}_{\boldsymbol{t}}$ is a $10 \times 1$ column vector for SPX Index, CCMP Index, SX5E Index, UKX Index, NKY Index, HSI Index, CNX 500 index, TA-100 Index, FTSE Top 40 Index and MXZA index at time $t . \alpha$ and $\psi$ are $10 \times 1$ and $10 \times 10$ matrices coefficients. $\omega_{t}$ is the $10 \times 1$ column of serially uncorrelated error terms. The $(i, j)$ th component of $\psi_{k}$ measures the direct effect on the $j$ th variable caused by the change in the ith variable after $k$ periods. In particular, the $i$ th component of $\omega_{t}$ is the innovation of the $i$ th variable that cannot be predicted by the other variables in the system (Greene 2003).

\section{Granger-causality test}

The VAR model is used as a means to examine the causality tests as specified by Granger (1969) and Sims (1972) when the lagged values of a variable, $x_{t}$ have explanatory power in regression of a variable $y_{t}$ on lagged values of $y_{t}$ and $x_{t}$. To establish and generalize the result, it is useful to form VAR in the multivariate regression format. Partition the two data vectors $y_{t}$ and $x_{t}$ into $[y 1 t, y 2 t]$ and $[x 1 t, x 2 t] . x_{1}$ are the lagged values of $y_{1}$; and $x_{2}$ are the lagged values of $y_{2}$ (Greene 2003). The VAR with partitioning could be written as

$$
\begin{aligned}
& {\left[\begin{array}{l}
\boldsymbol{y} 1 \\
\boldsymbol{y} 2
\end{array}\right]=\left[\begin{array}{ll}
\Gamma 11 & \Gamma_{12} \\
\Gamma_{21} & \Gamma_{22}
\end{array}\right]\left[\begin{array}{l}
\boldsymbol{x}_{1} \\
\boldsymbol{x}_{2}
\end{array}\right]+\left[\begin{array}{l}
\varepsilon_{1} \\
\varepsilon_{2}
\end{array}\right],} \\
& \operatorname{Var}\left[\begin{array}{l}
\varepsilon_{1 t} \\
\varepsilon_{2 t}
\end{array}\right]=\left[\begin{array}{ll}
\Sigma_{11} & \Sigma_{12} \\
\Sigma_{21} & \Sigma_{22}
\end{array}\right]
\end{aligned}
$$

Since causality determined earlier identifies significant effect on the future values of the respective variables in the model, it will be unable to unearth the direction of the relationship or the magnitude of the effects. An impulse response marks out the responsiveness of the endogenous variables in VAR to shock in the respective variable. One unit of shock is imposed on the error term of the respective variable, and its effect on VAR system over the time is observed. If the system is stable, then the shock would gradually die away.

Any VAR can be written as a first-order model by

$y_{t}=\mu+\Gamma_{1} y_{t-1}+\Gamma_{2} y_{t-2}+v_{t}$

can be written as

$\left[\begin{array}{c}\boldsymbol{y}_{\boldsymbol{t}} \\ \boldsymbol{y}_{\boldsymbol{t}-2}\end{array}\right]=\left[\begin{array}{c}\mu \\ 0\end{array}\right]+\left[\begin{array}{cc}\Gamma_{1} & \Gamma_{2} \\ \mathrm{I} & 0\end{array}\right]\left[\begin{array}{l}\boldsymbol{y}_{\boldsymbol{t}-1} \\ \boldsymbol{y}_{t-2}\end{array}\right]+\left[\begin{array}{c}v_{1} \\ 0\end{array}\right]$,

which is a first-order model. The dynamic characteristics of the model exist in either form, although the second one is subsequently considered convenient. In the model

$$
y_{t}=\mu+\Gamma_{1} y_{t-1}+v_{t}
$$

dynamic stability is achieved if the characteristics roots of $\Gamma$ have modulus less than one. Assuming that the equation system is stable, the equilibrium is found by obtaining the final form of the system:

$$
y_{t}=\mu+\Gamma(L) y_{t}+v_{t},
$$

or

$[\mathrm{I}-\Gamma(L)] y_{t}=\mu+v_{t}$.

With the stability condition, we have

Impulse response function and variance decomposition function 


$$
\begin{aligned}
\boldsymbol{y}_{\boldsymbol{t}} & =[\mathrm{I}-\Gamma(\boldsymbol{L})]^{-1}\left(\mu+\boldsymbol{v}_{\boldsymbol{t}}\right) \\
& =(\mathrm{I}-\Gamma)^{-1} \mu+\sum_{i=0}^{\infty} \Gamma^{i} \boldsymbol{v}_{t-1} \\
& =\overline{\boldsymbol{y}}+\sum_{i=0}^{\infty} \Gamma^{i} \boldsymbol{v}_{t-1} \\
& =\bar{y}+\boldsymbol{v}_{\boldsymbol{t}}+\Gamma \boldsymbol{v}_{t-1}+\Gamma^{2} \boldsymbol{v}_{t-2}+\ldots
\end{aligned}
$$

Suppose that $v$ is equal to 0 for long enough time so that $\mathrm{y}$ has reached equilibrium: $\bar{y}$. Now consider ejecting a shock to the system by changing one of the $v$ 's for one period, and then returning to its equilibrium. The path whereby the variables return to the equilibrium is called the impulse response of the VAR.

Consider then the effect of a one-time shock to the system, $\mathrm{d} v_{m t}$. Compared with the equilibrium, in the current period, we have

$y_{m t}-\bar{y}_{m}=d v_{m t}=\phi_{m m}(0) d v_{t}$

One period later, we have

$\boldsymbol{y}_{m, t+t}-\bar{y}_{m}=(\Gamma)_{m m} d v_{m t}=\phi_{m m}(1) d v_{t}$.

Two periods later, we have

$\boldsymbol{y}_{m, t+2}-\bar{y}_{m}=\left(\Gamma^{2}\right)_{m m} d v_{m t}=\phi_{m m}(2) d v_{t}$,

and so on. The function $\phi_{m m}$ gives the impulse response characteristics of variable $y_{m}$ to innovations in $v_{m}$. A useful way to characterize the system is to plot the impulse response functions. The former traces through the effect on variable $m$ of a one-time innovation in $v_{m}$ (Greene 2003). For the effect of a one-time innovation of $v_{t}$ on variable $m$, the impulse response function would be

$\phi_{m l}(i)=\operatorname{element}(m, l)$ in $\Gamma^{i}$

Further, the study used variance decomposition analyses to unlock the interrelationships among the SPX Index, CCMP Index, SX5E Index, UKX Index, NKY Index, HSI Index, CNX 500 index, TA-100 Index, FTSE Top 40 Index and MXZA index. Moreover, it also helps us determine the forecast error variance of a given variable which is explained by innovations to each explanatory variables for $s=1,2, \ldots, n$.

\section{Autoregressive conditional heteroskedastic $(\mathrm{ARCH})$ model}

The variance of the disturbance term is assumed to be constant. However, the economic time-series exhibit periods of unusually large volatility, followed by periods of relative tranquility, in such scenario, the assumption of a constant variance (homoskedasticity) is inappropriate (Enders 2004)

$\hat{\varepsilon}_{t}^{2}=\alpha_{0}+\alpha_{1} \hat{\varepsilon}_{t-1}^{2}+\alpha_{2} \hat{\varepsilon}_{t-2}^{2}+\cdots+\alpha_{q} \hat{\varepsilon}_{t-q}^{2}+v_{t}$

where $v_{t}$ is a white-noise process (error-term), if the values of $\alpha_{1}, \alpha_{2}, \ldots, \alpha_{n}$ are all equal zero, the estimated variance is simply the constant $\alpha_{0}$. If not, the conditional variance of $y_{t}$ evolves according to the autoregressive process given in Eq. (17). Hence, it is called an Autoregressive conditional heteroskedastic model (ARCH).

\section{Generalized autoregressive} conditional heteroskedastic (GARCH) model

Bollerslev's (1986) work allows the conditional variance to be an ARMA process. Let the error process be such that

$\varepsilon_{t}=v_{t} \sqrt{h_{t}}$

where $\sigma_{v}^{2}=1$ and

$$
h_{t}=\alpha_{0}+\sum_{i=1}^{q} \alpha_{i} \varepsilon_{t-i}^{2}+\sum_{i=1}^{p} \beta_{i} h_{t-i}
$$

Since $\left\{v_{t}\right\}$ is a white-noise process, the conditional and unconditional means of $e_{t}$ are equal to zero. Taking the expected value of $e_{t}$, it is easy to verify that

$$
E \varepsilon_{t}=E v_{t}\left(\mathrm{~h}_{\mathrm{t}}\right)^{1 / 2}=0
$$


The conditional variance of $e_{t}$ is given by $E_{t-1} \varepsilon_{t}^{2}=h_{t}$. Thus, the conditional variance of $\varepsilon_{t}$ is the ARMA process given by the expression $h_{t}$ in Eq. (18), and hence, the generalized $\operatorname{ARCH}(p, q)$ model called $\operatorname{GARCH}(p, q)$ allows for both autoregressive and moving average components in heteroskedastic variance. The present study estimates $\operatorname{GARCH}(1,1)$ specification (Enders 2004).

While the causation and the effect on each individual stock market have been examined, the longterm relationship is in foray, and hence, innovations in the OLS sharpens the predictability in the overall study period, and hence, the periods proceed through sectional phases namely, pre-subprime crisis, during crisis and crisis and post-subprime crisis periods. The mathematical expressions to examine the individual stock market behavioral aspect of variations in returns regressed on the rest of stock indices with innovations in time-series regressions are shown below:

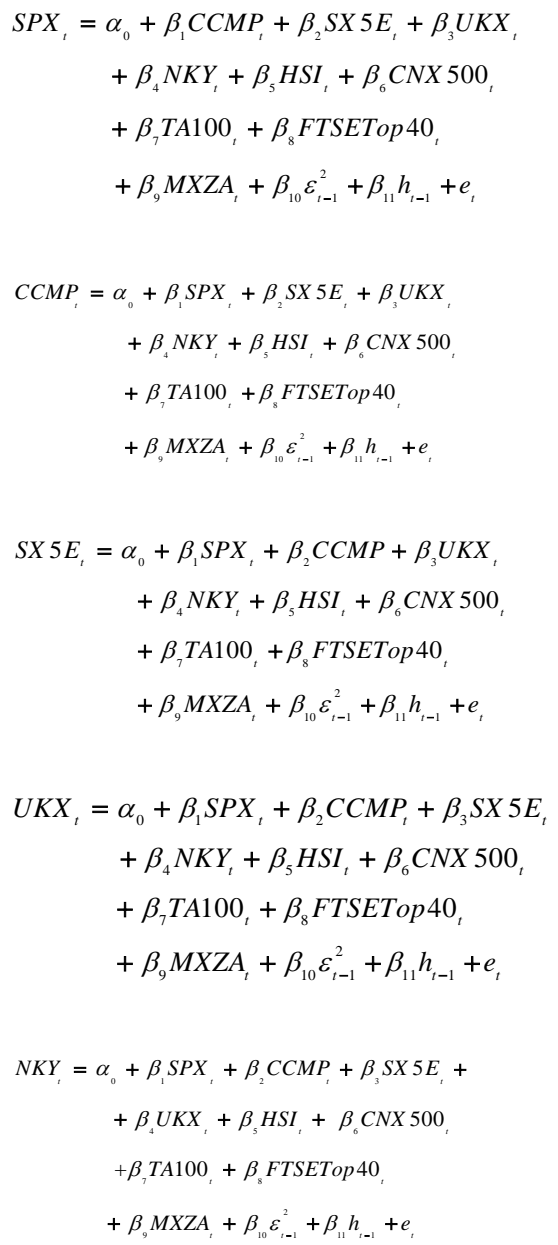

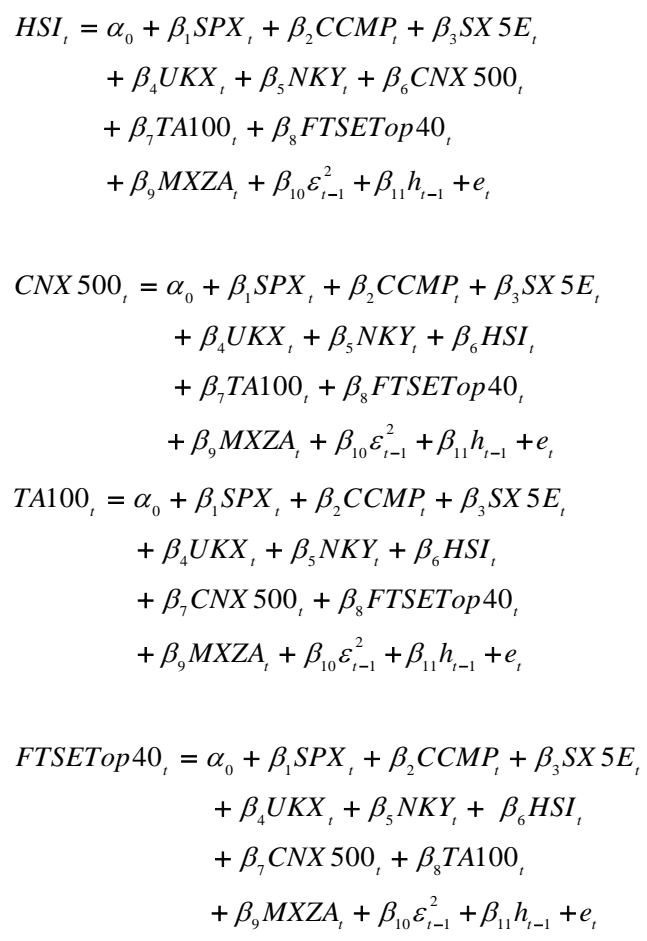

\section{Data}

The study examines the world market linkages and persistence of time-varying global financial market inefficiency, and thus the stock indices have been sorted on the basis of market capitalization of major world-wide economies represented by Americas, Europe, Middle East, Asia/Pacific and Africa, respectively. S\&P 500 index and NASDAQ Composite Index represent Americas indices; FTSE 100 Index and Euro STO 50 Price index represent European Indices; HANG SENG Index, Nikkei 225 and CNX 500 Equity Index represent Asia/Pacific Indices; TA-100 Index represents Middle East Indices; and FTSE/JSE Top 40 Index and MSCI South Africa Index represent African Indices.

The data sample for the study period comprised the monthly stock returns on the SPX Index, CCMP Index, SX5E Index, UKX Index, NKY Index, HSI Index, CNX 500 index, TA-100 Index, 
FTSE Top 40 Index and MXZA index, respectively, to represent the global financial market. The data period ranged from January 1996 to December 2013. The dataset of eighteen years is collected from Bloomberg database, representing the all indices' stock returns in rupees unit.

The sample and study period have been further categorized in line with the specification used by Dungey et al. (2008) and Karim and Karim (2012) to classify period into subsets as 1st January 1996 to 31st June 2007; 1st July 2007 to 31st December 2008; 1st January 2009 to 31st December 2013 for presubprime crisis, during subprime crisis, and postsubprime crisis, respectively.

Table 1 Descriptive statistics of global index returns for pre-crisis, during crisis and post-crisis periods

\begin{tabular}{|c|c|c|c|c|c|c|}
\hline Global market indices & Mean & Median & SD & Skewness & Kurtosis & Jarque-Bera \\
\hline \multicolumn{7}{|c|}{ Panel A: full sample period (January 1, 1996 to December 31, 2013) } \\
\hline \multicolumn{7}{|l|}{ Americas indices } \\
\hline SPX & 4.755 & 2.824 & 12.681 & 0.607 & 4.285 & $28.104 * * *$ \\
\hline CCMP & 6.161 & 3.420 & 18.686 & 0.539 & 4.740 & $31.719 * * *$ \\
\hline \multicolumn{7}{|l|}{ European indices } \\
\hline SX5E & 2.569 & 2.280 & 16.050 & 0.268 & 3.603 & $5.855^{* *}$ \\
\hline UKX & 2.425 & 1.335 & 12.330 & 0.017 & 3.288 & 0.758 \\
\hline \multicolumn{7}{|l|}{ Asia/Pacific indices } \\
\hline NKY & 1.666 & 1.014 & 14.305 & 1.018 & 5.428 & $90.329 * * *$ \\
\hline HSI & 3.707 & 1.692 & 17.048 & 0.675 & 4.214 & $29.712 * * *$ \\
\hline CNX 500 & 6.863 & 4.202 & 26.429 & 0.860 & 4.634 & $50.643 * * *$ \\
\hline \multicolumn{7}{|l|}{ Middle-East index } \\
\hline TA-100 & 7.458 & 4.579 & 20.786 & 0.718 & 3.979 & $27.177 * * *$ \\
\hline \multicolumn{7}{|l|}{ African indices } \\
\hline FTSE Top 40 & 4.753 & 3.641 & 16.511 & 0.741 & 4.487 & $39.670 * * *$ \\
\hline MXZA & 3.111 & 1.714 & 15.423 & 0.554 & 3.702 & $15.496 * * *$ \\
\hline \multicolumn{7}{|c|}{ Panel B: pre-crisis period (January 1, 1996 to June 30, 2007) } \\
\hline \multicolumn{7}{|l|}{ Americas indices } \\
\hline SPX & 4.403 & 3.060 & 12.085 & 0.365 & 4.171 & $10.939 * * *$ \\
\hline CCMP & 4.717 & 2.282 & 19.744 & 0.550 & 4.948 & $28.786 * * *$ \\
\hline \multicolumn{7}{|l|}{ European indices } \\
\hline SX5E & 4.421 & 2.842 & 15.831 & 0.366 & 3.841 & $7.146^{* *}$ \\
\hline UKX & 2.536 & 1.698 & 11.583 & 0.147 & 2.502 & 1.925 \\
\hline \multicolumn{7}{|l|}{ Asia/Pacific indices } \\
\hline NKY & 1.051 & 1.380 & 14.844 & 0.900 & 5.477 & $53.925 * * *$ \\
\hline HSI & 3.157 & 1.054 & 16.478 & 0.888 & 4.973 & $40.526 * * *$ \\
\hline CNX 500 & 7.832 & 6.112 & 23.334 & 1.269 & 5.659 & $77.675 * * *$ \\
\hline \multicolumn{7}{|l|}{ Middle-East index } \\
\hline TA-100 & 6.567 & 5.211 & 20.019 & 0.426 & 3.191 & 4.196 \\
\hline \multicolumn{7}{|l|}{ African indices } \\
\hline FTSE Top 40 & 5.441 & 4.521 & 16.501 & 0.762 & 4.219 & $21.901 * * *$ \\
\hline MXZA & 3.604 & 2.702 & 15.432 & 0.381 & 3.327 & 3.962 \\
\hline \multicolumn{7}{|c|}{ Panel C: subprime crisis period (July 1, 2007 to December 31, 2008) } \\
\hline \multicolumn{7}{|l|}{ Americas indices } \\
\hline SPX & -7.602 & -6.226 & 6.861 & -1.338 & 3.960 & $6.061 * *$ \\
\hline CCMP & -7.275 & -5.521 & 9.102 & -0.948 & 3.016 & 2.694 \\
\hline
\end{tabular}




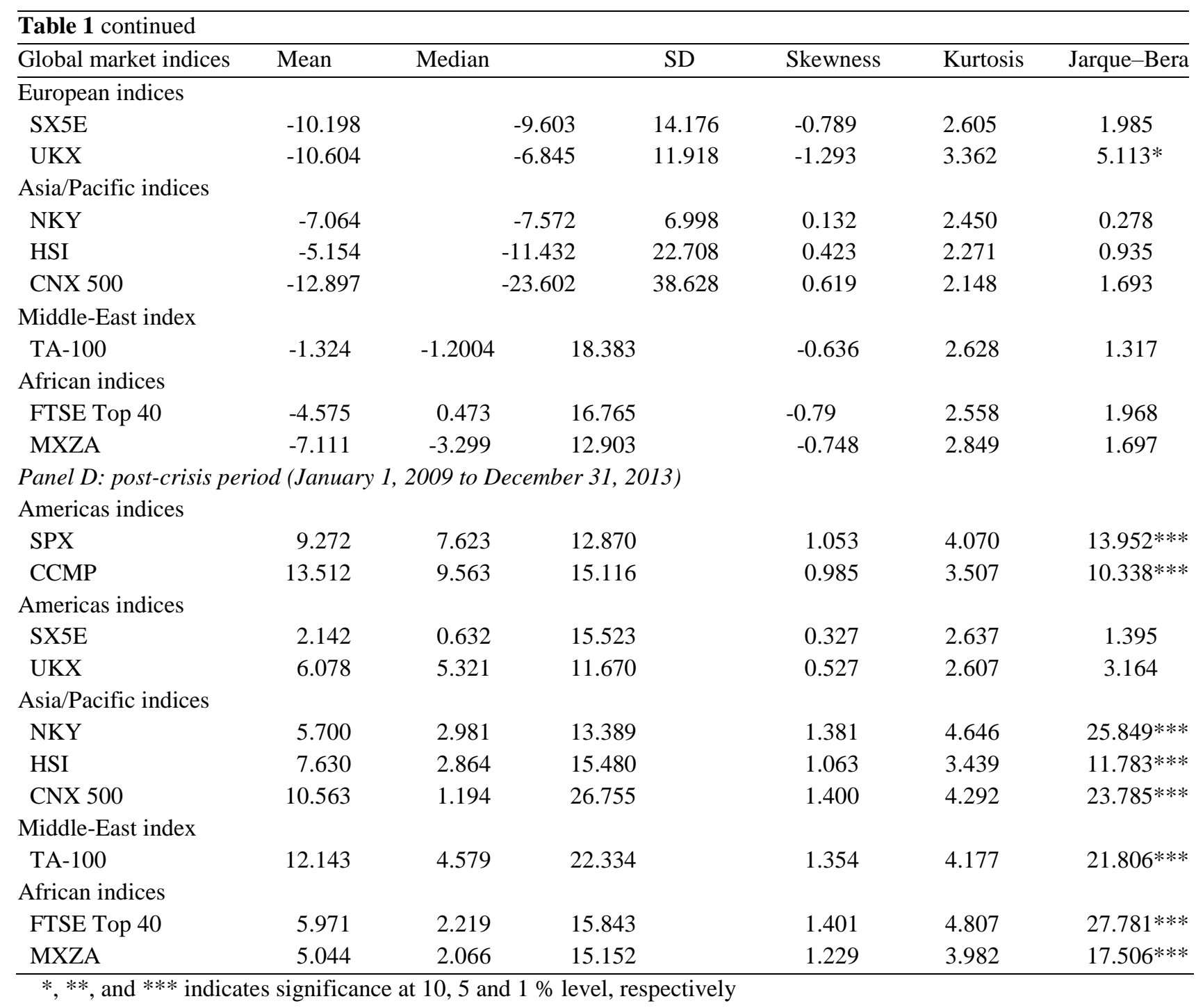

\section{Descriptive statistics}

The Table 1 presents the statistical inferences for the major global market indices mimicking SPX Index, CCMP Index, SX5E Index, UKX Index, NKY Index, HSI Index, CNX 500 index, TA-100 Index, FTSE Top 40 Index and MXZA index during the study period, January 1996 through December 2013. CNX 500 (6.863), CCMP (6.161) and TA-100 (7.458) stock indices remain top through incurring high mean returns over the study period compared to the remaining seven indices incurring mean returns. However, all the three highest grosser mean returns indices simultaneously show high variations over the study period incurring 26.429 for CNX 500, 20.786 for TA-100 and 18.686 for CCMP stock indices, respectively. The variations among the mean returns can be inferred through Table 1 of Panels A, B, C and D. However, panel $\mathrm{C}$ of Table 1 presents the statistics for the subprime crisis period, and hence, all the ten major stock indices representing the global economy suffers the bottom low trend through incurring negative returns over the crisis periods with relatively high variations. Thus, there is a strong indication that global financial stock market efficiency varies through time incurring the presence of high degree of global stock market inefficiency owing to the period of the catastrophe of subprime crisis.

With this seeming justification, the high correlations of approximately $80 \%$ shown in Table 2 for SPX index with CCMP, SX5E and UKX stock indices and of $70 \%$ approximately for CCMP index with SX5E, UKX, NKY and TA-100 provide further evidence for the global stock market linkages. $89 \%$ correlation among UKX and SX5E indices further adds up to the factual evidences. However, the high covariances among the indices also depict the higher co-movements in stock returns among the global stock indices, which set up the trends in stock returns as flaunting in the Fig. 1 and subsequently represent the graphical plot of each individual stock indices separately as well as jointly. Hence, at this juncture, the initial evidences promptly point towards global market dynamics with linkages among the global stock 
market indices and hence, befittingly account for global financial market inefficiency.

Table 2 Covariance and correlation coefficients of global market indices

\begin{tabular}{|c|c|c|c|c|c|c|c|c|c|c|}
\hline \multirow[t]{3}{*}{ Correlation } & \multicolumn{10}{|c|}{ Covariance } \\
\hline & $\overline{\text { SPX }}$ & CCMP & SX5E & UKX & NKY & HSI & CNX 500 & TA-100 & FTSE Top 40 & MXZA \\
\hline & INDEX & INDEX & INDEX & INDEX & INDEX & INDEX & INDEX & INDEX & INDEX & INDEX \\
\hline$\overline{\text { SPX INDEX }}$ & - & 206.194 & 172.418 & 134.352 & 96.060 & 104.168 & 104.585 & 151.623 & 50.734 & 38.724 \\
\hline $\begin{array}{l}\text { CCMP } \\
\text { INDEX }\end{array}$ & 0.874 & - & 229.346 & 179.244 & 186.615 & 210.853 & 272.978 & 274.921 & 132.061 & 111.515 \\
\hline $\begin{array}{l}\text { SX5E } \\
\text { INDEX }\end{array}$ & 0.851 & 0.768 & - & 176.624 & 109.216 & 142.311 & 172.810 & 181.881 & 79.906 & 56.716 \\
\hline $\begin{array}{l}\text { UKX } \\
\text { INDEX }\end{array}$ & 0.863 & 0.782 & 0.897 & - & 95.696 & 131.161 & 159.232 & 151.543 & 94.994 & 76.419 \\
\hline $\begin{array}{l}\text { NKY } \\
\text { INDEX }\end{array}$ & 0.532 & 0.701 & 0.478 & 0.545 & - & 149.584 & 193.582 & 145.191 & 145.425 & 119.77 \\
\hline HSI INDEX & 0.484 & 0.665 & 0.523 & 0.627 & 0.616 & - & 358.124 & 247.296 & 202.266 & 170.135 \\
\hline $\begin{array}{r}\text { CNX } 500 \\
\text { INDEX }\end{array}$ & 0.314 & 0.555 & 0.409 & 0.491 & 0.514 & 0.799 & - & 395.663 & 340.138 & 314.278 \\
\hline $\begin{array}{l}\text { TA-100 } \\
\text { INDEX }\end{array}$ & 0.578 & 0.711 & 0.548 & 0.594 & 0.491 & 0.701 & 0.724 & - & 204.922 & 183.642 \\
\hline $\begin{array}{l}\text { FTSE Top } 40 \\
\text { INDEX }\end{array}$ & 0.243 & 0.430 & 0.303 & 0.469 & 0.619 & 0.722 & 0.783 & 0.600 & - & 246.807 \\
\hline $\begin{array}{l}\text { MXZA } \\
\text { INDEX }\end{array}$ & 0.199 & 0.389 & 0.230 & 0.404 & 0.545 & 0.650 & 0.775 & 0.576 & 0.974 & - \\
\hline
\end{tabular}

Covariance coefficients are in bold face above the diagonal

Correlation coefficients are in normal with italic face below the diagonal

\section{Results}

The linkages among global stock indices and stock market dynamics process provide ample opportunity sets for the investors' eyes to minimize the risk through holding the different sizes of stocks and other financial instruments in the form of portfolio. Hence, through investing in diversified portfolio, rational investors are facing the two kinds of risk namely, country risk and global specific risks. The extent of global stock market indices, which causes simultaneously the degrees of linkages, accounts for the variations in the global stock indices returns. Therefore, the VAR methodology and its specification have been an influential tool to measure and unlock the dynamic linkages among the global stock indices namely, SPX Index, CCMP Index, SX5E Index, UKX
Index, NKY Index, HSI Index, CNX 500 index, TA100 Index, FTSE Top 40 Index and MXZA index. The dynamic linkages between the markets create a joint efficiency in an internationally diversified portfolio.

Stationarity and lag length determination in VAR model

The VAR methodology has been employed to examine the global stock market linkages its dynamics. The test of stationarity for the different sets of global stock market indices has been performed, and the results are shown in Table 3 to infer the presence of unit roots in the respective returns series. The test has been conducted for the full sample period, and the results are shown in panel A of Table 1, and subsequently, the tests are conducted for the pre-subprime crisis period, 

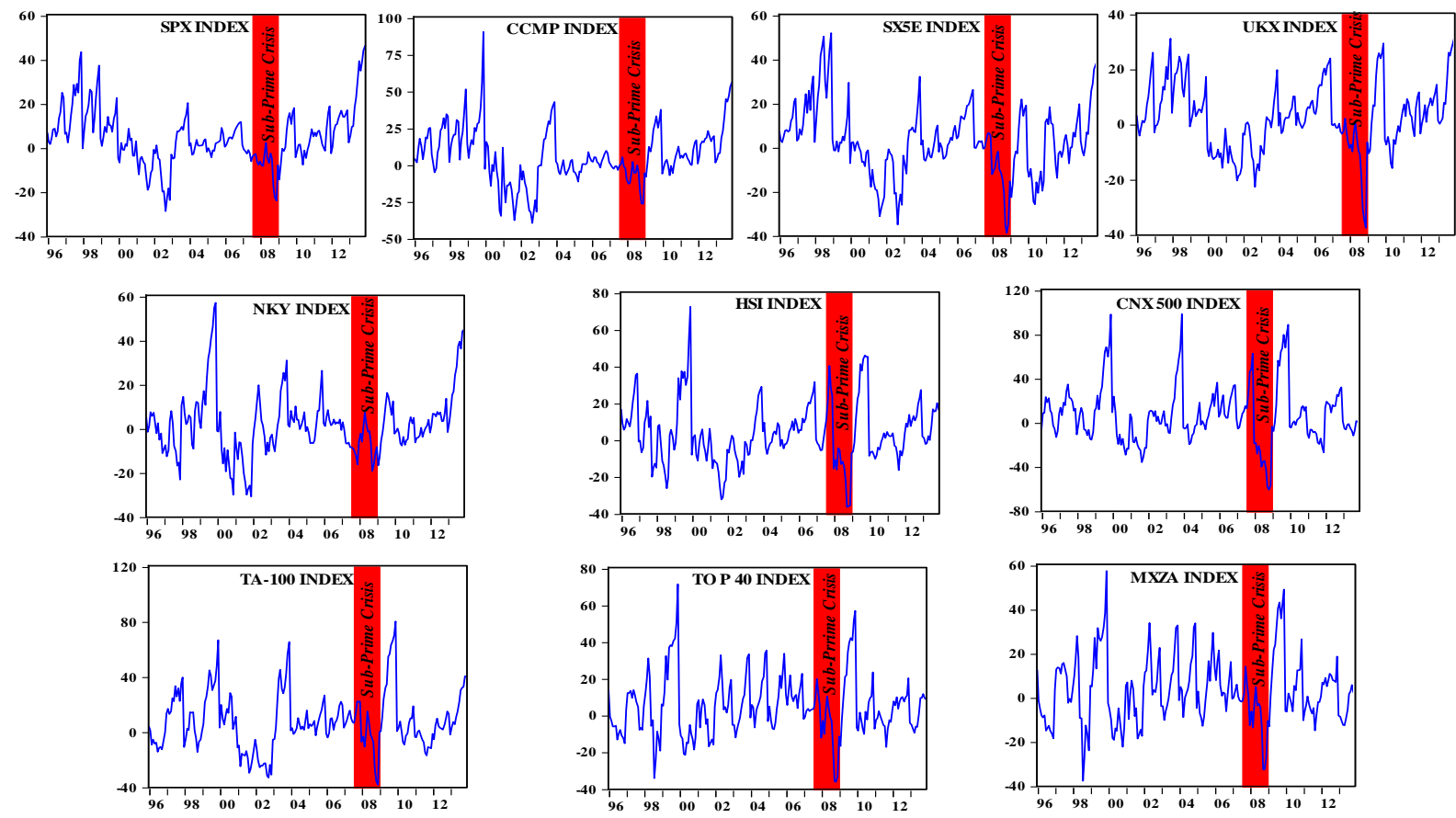

Fig. 1 Graphical representation of the major global indices NOTES: shaded area corresponds to subprime crisis period (July 1, 2007 to December 31, 2008)

during crisis period and post-subprime crisis period, as shown in panels $\mathrm{B}, \mathrm{C}$ and $\mathrm{D}$, respectively. The set of ten individual indices representing global stock indices returns series is found statistically significant at all conventional levels and concluded to be stationary for the full sample period; however, in the case of pre-subprime period, all the index returns series are found significant at first difference, and hence, series with differences have been taken into consideration for the purpose of analysis. The global stock indices returns series are found significantly different for the crisis period, however, with the exceptions of SPX, UKX and NKY stock indices which are subsequently found stationary at second difference and have simultaneously been transformed to make the series stationary. In post-subprime crisis sample period, all the stock indices are found stationary at first difference with the exceptions of FTSE Top 40 and MXZA indices, which subsequently are stationary at level and statistically significant at all conventional levels, and hence, the stationarity series are taken into account for the purpose of further analysis.

The lag length tests were conducted for the global stock indices, namely, SPX Index, CCMP
Index, SX5E Index, UKX Index, NKY Index, HSI Index, CNX 500 index, TA-100 Index, FTSE Top 40 Index and MXZA, for satisfying the VAR conditional assumptions and specification for the respective applications, and hence, analysis indicates one as optimum lag length based on AIC, LR and FPE tests as presented in Table 6 .

\section{Stability of VAR model}

The stability of the VAR model has been tested through AR roots graph developed by Lütkepohl (1991), and the results indicated inverse roots of the characteristic AR polynomial. A separate set of tests is conducted to diagnose the stability of the model used in the present study, and hence, the stability test has shown that all the inverse roots of the global stock indices possess modulus less than one and lie inside the unit circle as shown in Figs. 2, 3. Hence, the figure reveals the stability of the VAR model used further for the analysis purpose. 
Table 3 Unit root test of global market returns indices

\begin{tabular}{|c|c|c|c|c|c|c|}
\hline \multirow[t]{2}{*}{ Global market indices } & \multicolumn{2}{|l|}{ Level } & \multicolumn{2}{|l|}{ 1st difference } & \multicolumn{2}{|c|}{ 2nd difference } \\
\hline & ADF t-Stat & PP t-Stat & ADF t-Stat & PP t-Stat & ADF t-Stat & PP t-Stat \\
\hline \multicolumn{7}{|c|}{ Panel A: full sample period (January 1, 1996 to December 31, 2013) } \\
\hline \multicolumn{7}{|l|}{ Americas indices } \\
\hline SPX & $-3.62 * * *$ & $-3.36 * * *$ & - & - & - & - \\
\hline CCMP & $-4.55 * * *$ & $-4.39 * * *$ & - & - & - & - \\
\hline \multicolumn{7}{|l|}{ Americas indices } \\
\hline SX5E & $-3.87 * * *$ & $-3.83 * * *$ & - & - & - & - \\
\hline UKX & $-3.98 * * *$ & $-4.06 * * *$ & - & - & - & - \\
\hline \multicolumn{7}{|l|}{ Asia/Pacific indices } \\
\hline NKY & $-3.80 * * *$ & $-4.02 * * *$ & - & - & - & - \\
\hline HSI & $-5.03 * * *$ & $-5.08 * * *$ & - & - & - & - \\
\hline CNX 500 & $-4.91 * * *$ & $-5.22 * * *$ & - & - & - & - \\
\hline \multicolumn{7}{|l|}{ Middle-East index } \\
\hline TA-100 & $-4.33 * * *$ & $-4.42 * * *$ & - & - & - & - \\
\hline \multicolumn{7}{|l|}{ African indices } \\
\hline FTSE TOP 40 & $-5.63 * * *$ & $-5.91 * * *$ & - & - & - & - \\
\hline MXZA & $-5.68 * * *$ & $-5.99 * * *$ & - & - & - & - \\
\hline \multicolumn{7}{|c|}{ Panel B: pre-crisis period (January 1, 1996 to June 30, 2007) } \\
\hline \multicolumn{7}{|l|}{ Americas indices } \\
\hline SPX & $-3.84 * * *$ & $-3.64 * * *$ & - & - & - & - \\
\hline CCMP & $-4.26 * * *$ & $-4.09 * * *$ & - & - & - & - \\
\hline \multicolumn{7}{|l|}{ Americas indices } \\
\hline SX5E & $-3.56 * * *$ & $-3.40 * * *$ & - & - & - & - \\
\hline UKX & $-3.56 * * *$ & $-3.55 * * *$ & - & - & - & - \\
\hline \multicolumn{7}{|l|}{ Asia/Pacific indices } \\
\hline NKY & $-3.86 * * *$ & $-4.02 * * *$ & - & - & - & - \\
\hline HSI & $-4.33 * * *$ & $-4.33 * * *$ & - & - & - & - \\
\hline CNX 500 & $-4.22 * * *$ & $-4.42 * * *$ & - & - & - & - \\
\hline \multicolumn{7}{|l|}{ Middle-East index } \\
\hline TA-100 & $-3.73 * * *$ & $-3.69 * * *$ & - & - & - & - \\
\hline \multicolumn{7}{|l|}{ African indices } \\
\hline FTSE Top 40 & $-4.66 * * *$ & $-4.76 * * *$ & - & - & - & - \\
\hline MXZA & $-4.71 * * *$ & $-4.83 * * *$ & - & - & - & - \\
\hline \multicolumn{7}{|c|}{ Panel C: subprime crisis period (July 1, 2007 to December 31, 2008) } \\
\hline \multicolumn{7}{|l|}{ Americas indices } \\
\hline SPX & -0.43 & -0.21 & -0.14 & $-3.10 * *$ & $-8.23 * * *$ & $-6.02 * * *$ \\
\hline CCMP & -1.42 & -0.46 & $-3.11 * *$ & $-3.03 * *$ & - & - \\
\hline \multicolumn{7}{|l|}{ Americas indices } \\
\hline SX5E & -0.22 & -0.34 & $-3.17 * *$ & $-3.06 * *$ & - & - \\
\hline UKX & 0.97 & 0.72 & -2.66 & -2.62 & $-4.66 * * *$ & $-9.46^{* * *}$ \\
\hline \multicolumn{7}{|l|}{ Asia/Pacific indices } \\
\hline NKY & -2.59 & -1.75 & -1.16 & $-3.34 * *$ & $-6.73 * * *$ & $-7.23 * * *$ \\
\hline HSI & -0.76 & -0.92 & $-3.67 * * *$ & $-3.78 * * *$ & - & - \\
\hline CNX 500 & -0.97 & -0.93 & $-4.35 * * *$ & $-4.35 * * *$ & - & - \\
\hline \multicolumn{7}{|l|}{ Middle-East index } \\
\hline TA-100 & -0.31 & -0.46 & $-3.54 * *$ & $-3.54 * *$ & - & - \\
\hline African indices & & & & & & \\
\hline FTSE Top 40 & -0.52 & -0.68 & $-3.31 * *$ & $-3.31 * *$ & - & - \\
\hline
\end{tabular}


Table 3 Continued

\begin{tabular}{|c|c|c|c|c|c|c|}
\hline \multirow[t]{2}{*}{ Global market indices } & \multicolumn{2}{|l|}{ Level } & \multicolumn{2}{|c|}{ 1st difference } & \multicolumn{2}{|c|}{ 2nd difference } \\
\hline & $\overline{\mathrm{ADF}} \mathrm{t}-\mathrm{Stat}$ & PP t-Stat & ADF t-Stat & PP t-Stat & ADF t-Stat & PP t-Stat \\
\hline MXZA & -0.98 & -1.08 & $-3.69 * * *$ & $-3.68 * * *$ & - & - \\
\hline \multicolumn{7}{|c|}{ Panel D: post-crisis period (January 1, 2009 to December 31, 2013) } \\
\hline \multicolumn{7}{|l|}{ Americas indices } \\
\hline SPX & -0.99 & -0.84 & $-7.81 * * *$ & $-7.87 * * *$ & - & - \\
\hline CCMP & -1.44 & -1.45 & $-8.11 * * *$ & $-8.11 * * *$ & - & - \\
\hline \multicolumn{7}{|l|}{ Americas indices } \\
\hline SX5E & -1.51 & -1.78 & $-6.86 * * *$ & $-6.84 * * *$ & - & - \\
\hline UKX & -1.95 & -2.06 & $-7.47 * * *$ & $-7.47 * * *$ & - & - \\
\hline \multicolumn{7}{|l|}{ Asia/Pacific indices } \\
\hline NKY & -0.19 & -0.04 & $-8.48 * * *$ & $-8.42 * * *$ & - & - \\
\hline HSI & -2.44 & $-2.72 *$ & $-7.51 * * *$ & $-7.51 * * *$ & - & - \\
\hline CNX & & & & $-7.57 * * *$ & - & - \\
\hline 500 & -2.41 & -2.55 & $-7.57 * * *$ & e & - & \\
\hline \multicolumn{7}{|l|}{ Middle-East index } \\
\hline TA-100 & -2.05 & -2.17 & $-7.99 * * *$ & $-7.99 * * *$ & - & - \\
\hline \multicolumn{7}{|l|}{ African indices } \\
\hline FTSE Top 40 & $-3.06^{* *}$ & $-3.07 * *$ & - & - & - & - \\
\hline MXZA & $-3.01 * *$ & $-3.06^{* *}$ & - & - & - & - \\
\hline
\end{tabular}

ADF augmented Dickey-Fuller test, PP Phillips-Perron test

$*$,**, and $* * *$ indicates significance at 10,5 and $1 \%$ level, respectively

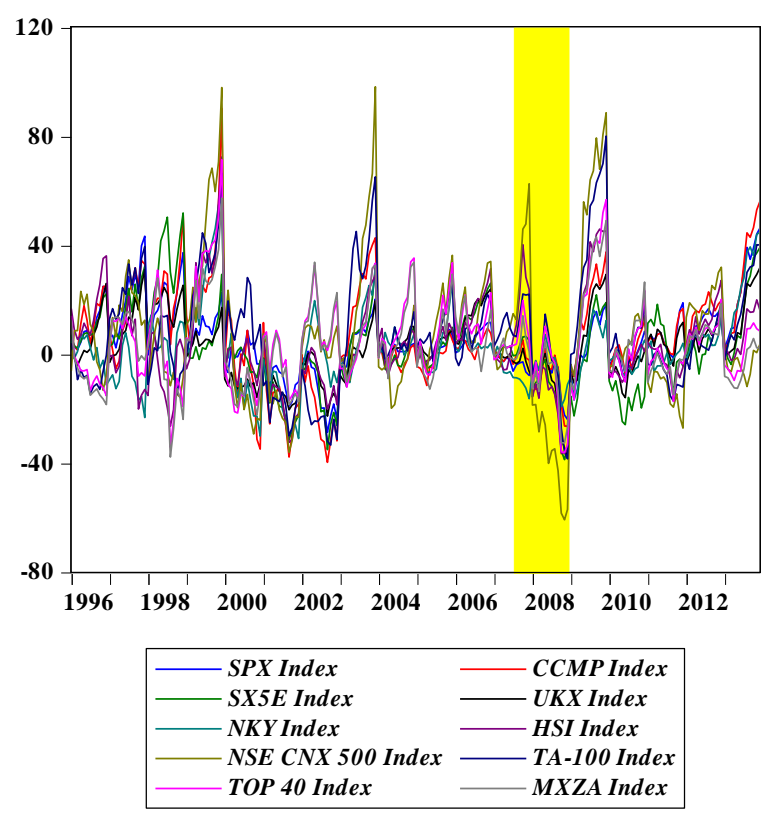

Fig. 2 Graphical Representation of all major Global Indices NOTES: Shaded area corresponds Sub-Prime Crisis Period (July 1, 2007 to December 31, 2008)
Inverse Roots of AR Characteristic Polynomial

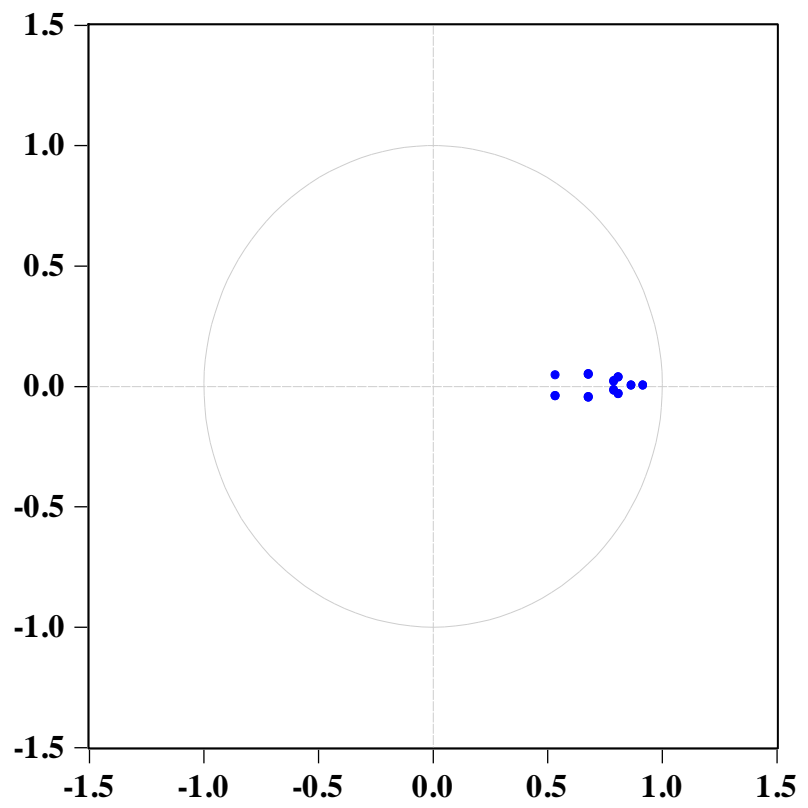

Fig. 3 VAR stability test of all major stock market indices 


\section{VAR estimation}

The persistence of global stock market linkages and the stock market dynamics have been supported with the empirical evidences extracted from VAR specifications namely, variance decomposition analysis and GIR impulse response function, with respect to major stock indices representing the world economy. Table 4 presents the VAR estimation outputs for the study period through regressing separately each of the individual stock market indices namely, SPX Index, CCMP Index, SX5E Index, UKX Index, NKY Index, HSI Index, CNX 500 index, TA100 Index, FTSE Top 40 Index and MXZA index on the respective indices' lagged values in respect of individual's own lags. The evidence from Table 4 indicates that approximately 70 percent of the coefficient of determination in the respective cases of regression accommodates to predict the future stock returns. However, Table 5 presents the VAR estimation output for the study period of subprime crisis, which indicates that the coefficients of determination have gone down drastically for SPX index from 70 to $47 \%$, CCMP index from 64 to $32 \%$, UKX index from 70 to $27 \%$, NKY index from 70 to $12 \%, \mathrm{CNX}-500$ index from 63 to $45 \%$, and FTSE Top-40 index from 56 to $45 \%$, respectively, with the exception of increases in the coefficients of determination during the subprime crisis period for SX5E index from 71 to $90 \%$, HSI index from 63 to 70 $\%$, TA-100 index from 67 to $77 \%$ and MXZA index from 56 to $67 \%$, respectively. Hence, the evident specification reveals drastic fluctuations in the coefficient of determination for the period of subprime crisis and, compared to the full sample period, which indicates the persistence of time-varying global stock market inefficiency apart from linkages among the global stock indices and subsequently varies through the time factor. Simultaneously, the unexpected emergence of catastrophic event of subprime crisis revealed that the co-movements in the variations of global stock returns experienced bottom low levels for SPX, CCMP, UKX, NKY, CNX-500, FTSE Top 40 stock indices respectively. However, the spill-over effect has not influenced the covariance in stock returns among SX5E, HSI, TA-100, MXZA stock indices; rather, the linkages among the indices have gone up for the period of subprime crisis, which indicates the dynamics in the global stock indices (Table 6).

\section{Granger causality tests}

The Granger-causality (Granger 1980) test is used for the purpose of interpretation of VAR specifications. A joint hypothesis of zero coefficients on all significant lag of global stock indices is examined using ' $F$ ' distribution. Hence, the interdependences among the global stock indices representing world economy have been tested to articulate the evidence for global market linkages through applying Wald tests on the joint significance of the lagged estimated coefficients of lagged values of SPX Index, CCMP Index, SX5E Index, UKX Index, NKY Index, HSI Index, CNX 500 index, TA-100 Index, FTSE Top 40 Index and MXZA index, respectively. The set of analysis presented in Table 7 indicates a causal relationship of SPX stock index with NKY stock index, which is found statistically significant at one percent significance level. Further, CCPM stock index indicating causality with NKY stock index at all conventional levels and TA-100 and FTSE TOP 40 stock also indicates causeand-effect relationship at 10 percent significance level. However, CCMP stock index indicates causality with all the global indices altogether at one percent significance level. SX5E and UKX stock indices indicate causality with NKY stock index and are found statistically significant at one percent level. NKY and HSI stock indices indicated causality with CCMP, SX5E, and CNX 500 stock indices, respectively, and were found significant at all conventional levels, and in addition, NKY and HSI indices indicate causality with all the stock indices collectively, which is found statistically significant at five percent level. Likewise, CNX 500 and TA-100 stock indices indicate causality with HSI stock index, which is found statistically significant at one percent level, although TA-100 also indicates causality with NKY, FTSE Top 40 and MXZA stock indices successively, which is found statistically significant at ten percent level.

MXZA stock index represents causality with SX5E and UKX stock indices at one and five percent significance levels, respectively, as presented in the Table 7. However, FTSE Top 40 stock index and MXZA stock index can cause through the lag information set of global stock indices altogether, which successively are significant at five percent level, respectively. All the above instances as evidence of causality-and-effect 
Table 4 Standard VAR estimations (full sample period-January 1, 1996 to December 31, 2013)

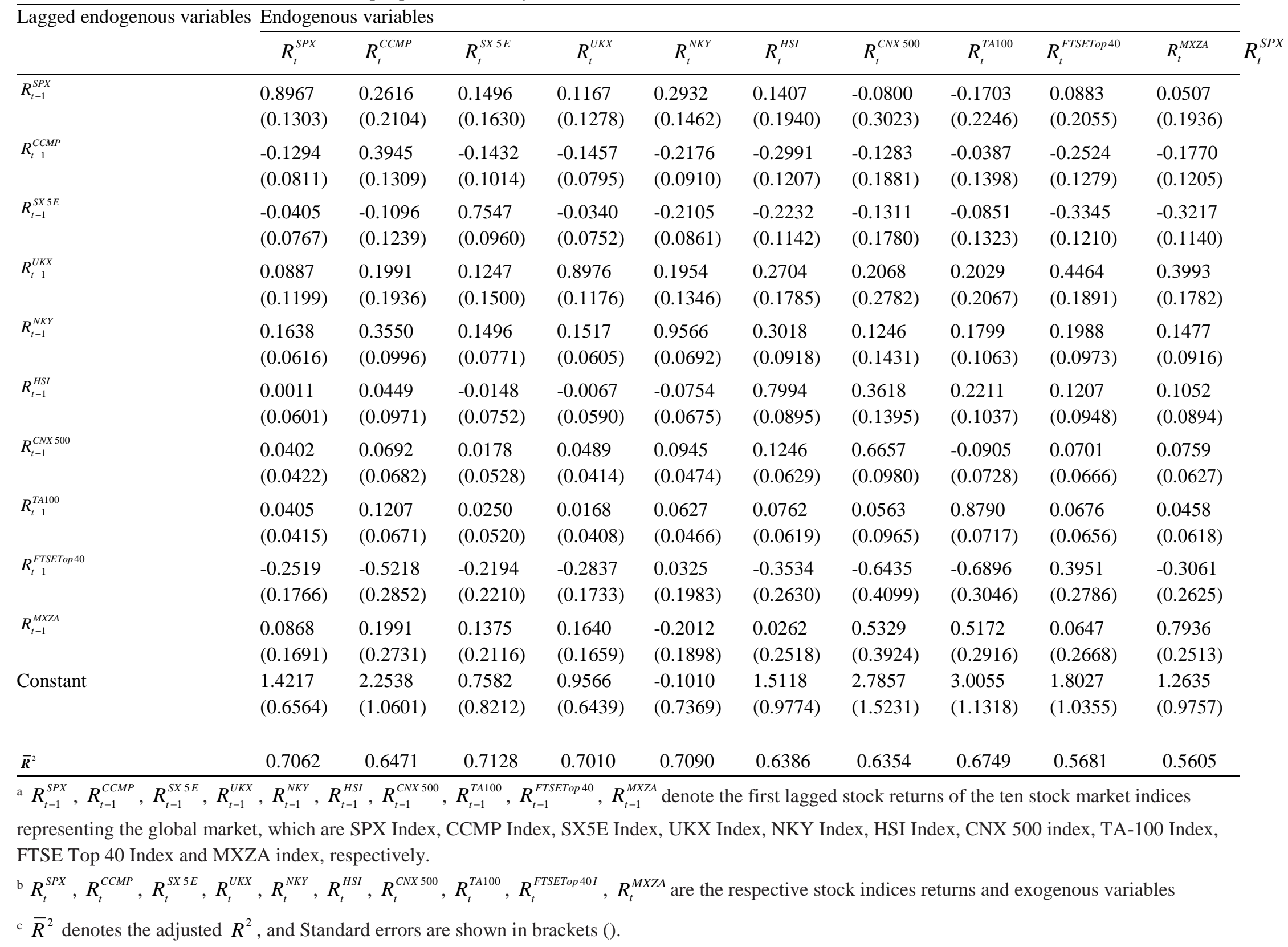


Table 5 Standard VAR estimations (Crisis Period—July 1, 2007 to December 31, 2008)

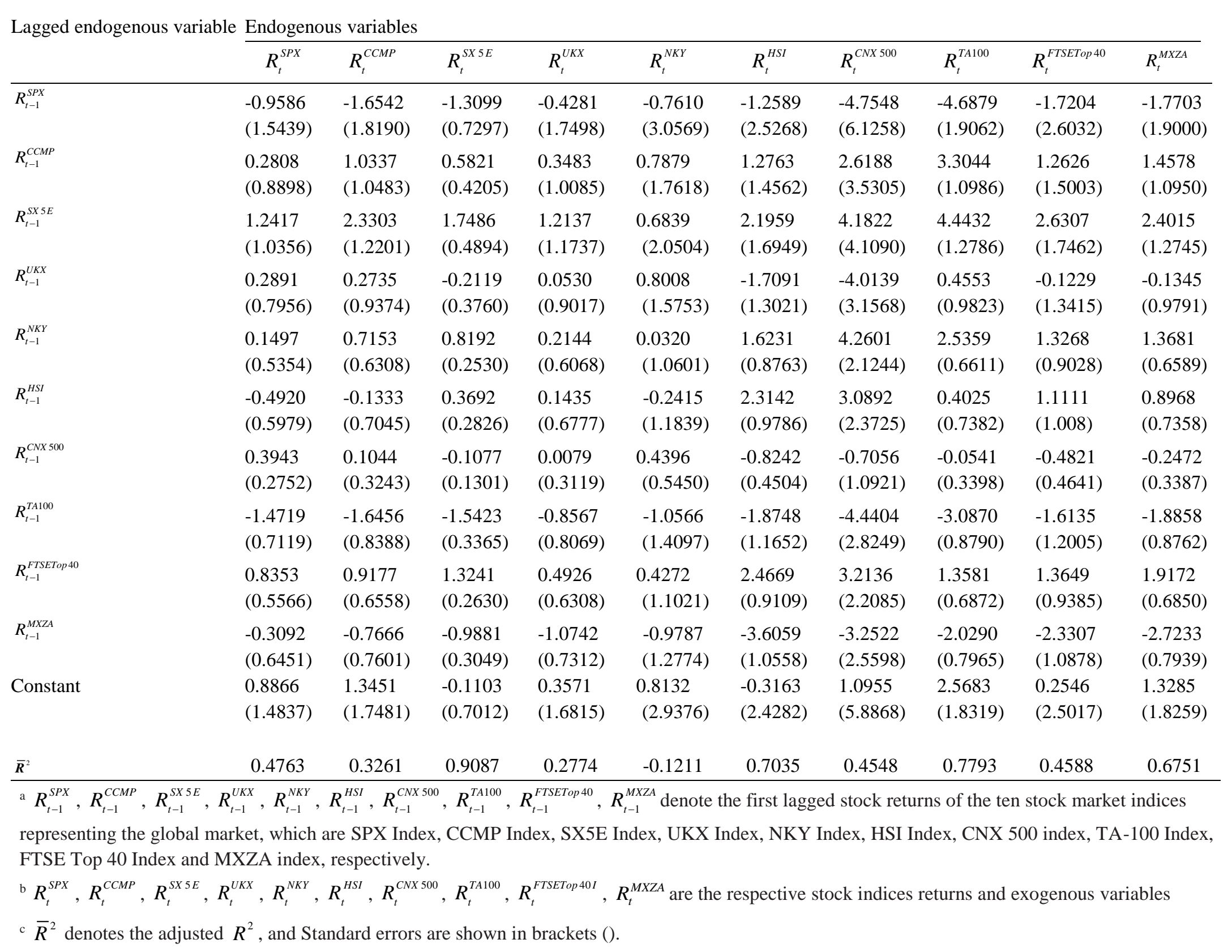


Table 6 Lag length determination for major global stock market indices

\begin{tabular}{lllllr}
\hline Lag & LR & FPE & AIC & SC & HQ \\
\hline 0 & NA & $3.44 \mathrm{e}+18$ & 71.0613 & 71.2217 & 71.1262 \\
1 & $1,883.490^{*}$ & $6.35 \mathrm{e}+14^{*}$ & $62.4620^{*}$ & $64.2270^{*}$ & $63.1757^{*}$ \\
\hline
\end{tabular}

* Indicates lag order selected by the criterion

$L R$ sequentially modified LR test statistic (each test at $5 \%$ level), FPE final prediction error, AIC Akaike information criterion, SC Schwarz information criterion, $H Q$ Hannan-Quinn information criterion

relationships among global stock indices with their respective lagged prices therefore replicate a strong signal for world stock market linkages and stock market dynamics for the short-horizon period.

Impulse response function

The dynamic linkages among the global stock indices returns have been examined with the generalized impulse response (GIR) function for the short-horizon period. The GIR functions of the significant variables are presented in Figs. 4, 5, 6, 7, 8, 9, 10, 11, 12 and 13, respectively. Figure 4 presents the response of SPX stock index to the shocks in the rest of the nine stock returns indices. The response of SPX index to shock in CCPM index is felt a little over a period of 9 month and dies out simultaneously. The responses of SPX stock index to shocks in UKX, CNX 500, SPX and MXZA stock indices were meagre and hence die out approximately at the end of the 6-month period. The response of CCMP stock index to the innovations in the rest of the indices is shown in Fig. 5. Responses of CCMP stock index to HSI, CNX 500, and TA-100 are significant though with very meagre response, and subsequently die out with the increase in duration approximately from the fifth month to last of the ninth month. However, response to the rest of stock indices establishes insignificant effect. The responses of SX5E stock index to the innovations in the rest of the stock indices are shown in Fig. 6. SX5E index responses were found significant towards HSI, FTSE TOP 40, and CNX 500 stock indices, and hence, the response felt was very meagre over the period with decaying trend. The UKX stock index response towards the shocks in the rest of the indices is found significant towards the response in CCMP stock index for first half of every month with positive followed by negative decaying trend over the period of ten months.
However, the rest of the responses of UKX stock index have not shown any significant response as presented in Fig. 7. NKY stock has not shown any response towards the innovations in the rest of the stock indices and with an exception of SX5E stock index with initial positive response partly for 1 month followed by negative response through the rest of the months presented in Fig. 8. However, HSI stock index has not shown significant response towards the innovations in the rest of the stock indices presented in the Fig. 9. The GIRs of CNX 500 stock index to the innovations in the rest of the stock indices are not statistically significant as shown in the Fig. 10. The GIR of TA-100 index to the shock in SX5E stock index is not showing any significant positive effect until the fifth month, after which negative response with decaying trend is observed for the rest of the period, and no other significant response is found towards the rest of the stock indices as indicated in the Fig. 11.

The GIR of FTSE Top 40 stock index to the innovations in the rest of the stock indices reveals the response to SX5E stock index: significant positive response until third month followed by negative decaying trend of the response for the rest of the period as shown in Fig. 12. The GIR of MXZA index to the innovations in SX5E stock index has shown a positive and significant effect until the second month, followed by the negative decaying trend for the rest of the period as presented in Fig. 12. Hence, the dynamics persistence in short-horizon relationship among the global stock indices has been discovered through shocks in state variables (global stock indices), and in turn, response of an individual stock index has been observed towards the innovations over the time period. The GIR towards an individual stock indices due to shock has unlocked impeccable and dynamic insights towards the movements and co-movements among the global stock indices resembling the linkages between 
global stock markets, and simultaneously providing evidence for the global stock market dynamics.

Variance decomposition analysis (VDA)

The result for the set of VDA analysis has been presented in the Table 8 for the global stock indices namely, SPX Index, CCMP Index, SX5E Index, UKX Index, NKY Index, HSI Index, CNX 500 index, TA100 Index, FTSE Top 40 Index and MXZA index. Panel A of Table 8 indicates that nearly 87 percent of the variance can be explained through its own innovations. However, NKY stock index explains approximately 3 percent of the variations at the end of the 10-month period. The forecast error variance of CCMP stock index presented in panel B of Table 8 indicates that a meagre 14 percent of the innovation was due to its own shock, with the remaining portion of 86 percent of the variations in returns being explained through SPX stock index. Hence, the first two set of panels evidenced that the SPX stock index plays the major factor in explaining the forecasting error variances of the SPX and CCMP stock returns.

Panel C of Table 8 presents the forecast error variance of SX5E stock index and indicates that 72 percent of variations can be explained through the SPX stock index, and a meagre 21 percent of innovations was due to its own shock. Conversely, 3 percent of variations in SX5E stock index can be explained by NKY stock index. However, Panel D of Table 8 indicates that 71 percent of variations in UKX stock index returns can be explained by the innovations in SPX stock index, and its own shock depicts meagre 13 percent. Panel E of Table 8 presents the variations in returns of NKY stock index, which are explained through its own shock by 54 percent, while shock of SPX stock index has explained 23 percent of variations in NKY stock index returns, and approximately 6 percent variations in returns of NKY index can be explained through MXZA stock index. Panel F of Table 8 presents the VDA result of the HSI stock index of the forecasting error variance and indicates that 28 percent of innovations in variation is explained through its own shock; conversely, 22 percent variations in returns has been explained by SPX stock index, and 10,11, 8 and $12 \%$ variations in returns of HIS stock index are explained by the shocks in CCMP, UKX, NKY, FTSE Top 40 indices, respectively. Panel G of Table 8 represents the VDA result of CNX 500 stock index and indicates that 31 percent of variance can be explained by its own shock, and 21 percent of variations can be explained due to shock in CCMP index. However, 11 percent of variations in returns of CNX 500 can be explained by SPX stock index, and 9 and 13 percent variations in CNX 500 stock index returns can be explained simultaneously by the shocks in UKX and HSI stock indices, respectively. However, it is evidenced that the variations in CNX 500 stock market index returns can be explained through various indices proportionally which reiterates that the movements in the Indian stock market have a balanced source of information that has been incorporated to measure the variations in returns and thus, provide evidence for the higher degree of linkages. The variations of returns in TA100 stock index are ascribed primarily to 33 percent of shocks in SPX stock index as shown in panel $\mathrm{H}$ of Table 8. Although 31 percent of variations can be converged through the innovations in its own shocks, 7 percent of variations in TA-100 stock index can be explained by shocks in both CCMP and CNX 500 stock indices. The forecast variance of FTSE Top 40 stock index presented in Table 8 of panel I indicates 18 percent of innovation was due to its own shock, and the remaining is explained by proportional shocks: SPX stock index (10 percent), CCMP stock index (10 percent), UKX stock index (25 percent), NKY stock index (14 percent), and HSI stock index by (8 percent), respectively. Panel $\mathrm{J}$ of Table 8 presents the forecast error variance in returns of MXZA stock index and indicates that 20 percent of innovation was due to shock in UKX stock index. However, its own shock forecast measures variance in returns is meagre 4 percent; 15 percent innovations is due to shock of CNX 500 stock index, and 11 percent innovations is due to shock in CCMP stock index, respectively. The above evidences from variance decomposition analysis confirm that the blend of lagged stock prices of an individual stock market and the corresponding counterparts play a crucial role to form and determine the asset pricing process.

\section{Time-varying global financial stock market inefficiency}

The persistence of the time-varying global financial stock market inefficiency and its dynamics has been 
Table 7 VAR ganger causality/ block exogeneity WALD tests

\begin{tabular}{|c|c|c|c|c|c|c|c|c|c|c|c|}
\hline \multirow[t]{2}{*}{ Endogenous Variable } & \multicolumn{11}{|c|}{ Lagged Endogenous Variables } \\
\hline & SPX & CCMP & SX5E & UKX & NKY & HSI & CNX 500 & TA100 & FTSE Top 40 & MXZA & ALL \\
\hline SPX & - & 2.5496 & 0.2790 & 0.5479 & $7.0553 * * *$ & 0.0003 & 0.9062 & 0.9529 & 2.0345 & 0.2634 & 10.6769 \\
\hline CCMP & 1.5462 & - & 0.7829 & 1.0573 & $12.7021 * * *$ & 0.2139 & 1.0294 & $3.2295^{*}$ & $3.3463 *$ & 0.5318 & $20.7215^{* * * *}$ \\
\hline SX5E & 0.8420 & 1.9923 & - & 0.6909 & $3.7611 * *$ & 0.0389 & 0.1145 & 0.2321 & 0.9861 & 0.4227 & 6.8233 \\
\hline UKX & 0.8342 & $3.3581^{*}$ & 0.2044 & - & $6.2910 * * *$ & 0.0131 & 1.3969 & 0.1697 & $2.6813^{*}$ & 0.9770 & 9.4712 \\
\hline NKY & $4.0193 * *$ & $5.7164 * * *$ & $5.9733 * * *$ & 2.1082 & - & 1.2492 & $3.9726^{* *}$ & 1.8055 & 0.0269 & 1.1237 & $18.0777^{* *}$ \\
\hline HIS & 0.5260 & $6.1359 * * *$ & $3.8178 * *$ & 2.2945 & $10.8030 * * *$ & - & $3.9300 * *$ & 1.5159 & 1.8050 & 0.0108 & $20.3807 * *$ \\
\hline CNX 500 & 0.0701 & 0.4655 & 0.5425 & 0.5526 & 0.7586 & $6.7202 * * *$ & - & 0.3410 & 2.4649 & 1.8443 & 9.4893 \\
\hline TA-100 & 0.5748 & 0.0766 & 0.4142 & 0.9630 & $2.8626^{*}$ & $4.5468 * *$ & 1.5471 & - & $5.1259 * *$ & $3.1462 *$ & 10.8858 \\
\hline FTSE Top 40 & 0.1846 & $3.8923^{* *}$ & $7.6391 * * *$ & $5.5699 * *$ & $4.1769 * *$ & 1.6202 & 1.1083 & 1.0619 & - & 0.0588 & $19.13047 * *$ \\
\hline MXZA & 0.0687 & 2.1578 & $7.9596 * * *$ & $5.0203 * *$ & 2.5967 & 1.3848 & 1.4625 & 0.5500 & 1.3598 & - & $17.3146^{* *}$ \\
\hline
\end{tabular}

Response of SPX INDEX to CCMP INDEX

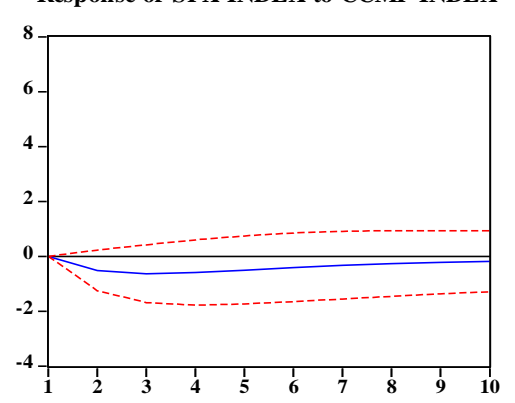

Response of SPX INDEX to NKY INDEX

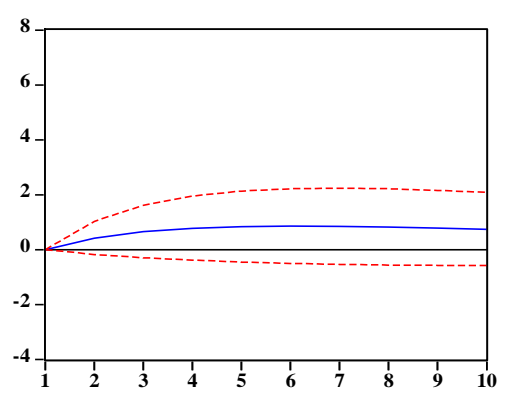

Response of SPX INDEX to TA-100 INDEX

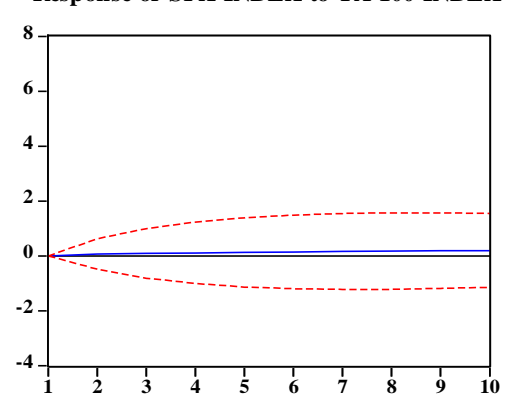

Response of SPX INDEX to SX5E INDEX

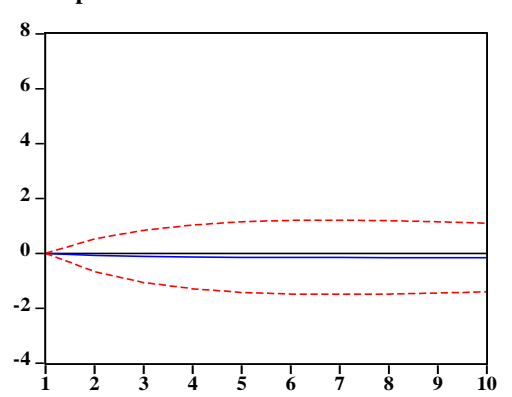

Response of SPX INDEX to HSI INDEX

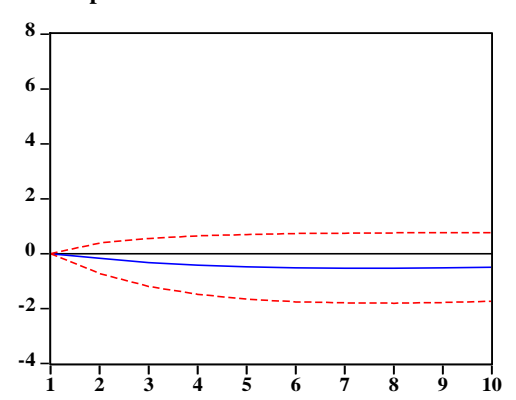

Response of SPX INDEX to FTSE TOP-40 INDEX

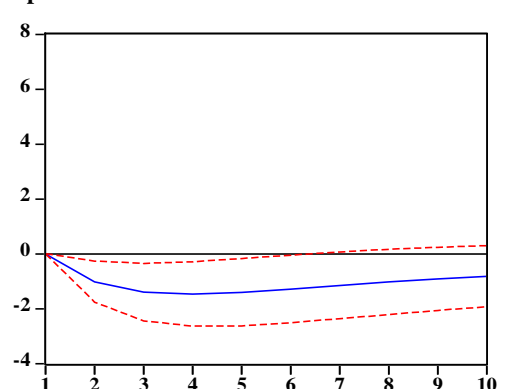

Response of SPX INDEX to UKX INDEX

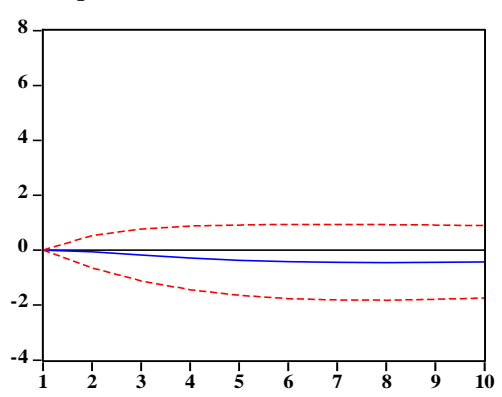

Response of SPX INDEX to CNX-500 INDEX

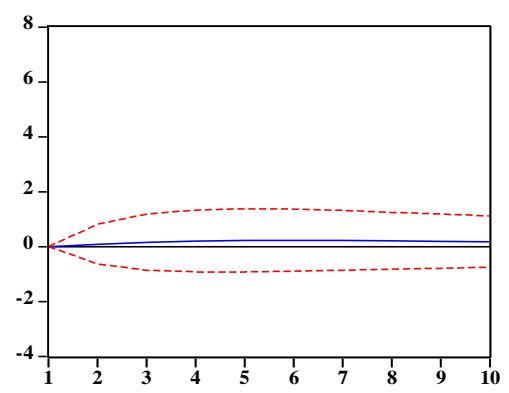

Response of SPX INDEX to MXZA INDEX

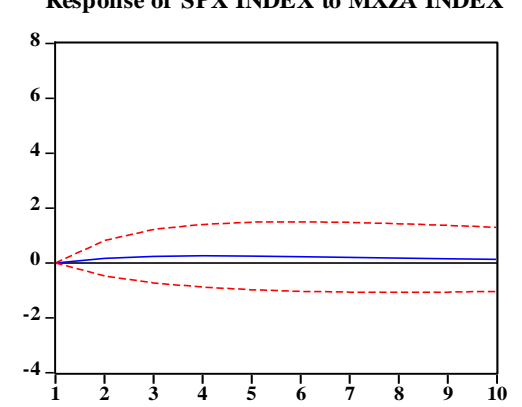

Fig. 4 GIRs of SPX to one S.E shock in CCMP, SX5E, UKX, NKY, HSI, CNX-500, TA-100, FTSE TOP-40 and MXZA 
examined with the means of global stock market indices representing the world economy for the full sample period, pre-subprime crisis period, subprime crisis period and post-subprime crisis period through time-varying regression including volatility specification owing generalized autoregressive model. The volatility factors reveal as an innovation and a shock to the state variables that captures the dynamics in the time variations representing the beta values. Table 9 presents the time-varying beta coefficients for the full sample period and hence panel A of Table 9 presents the time-varying regression specifications for SPX stock index regressed on the rest of the stock indices in the presence of volatility factor and trend as moving average. The specifications in Panel A Table 9 indicates that all the stock indices returns series have positive relationships with the SPX stock index returns with the exception of SX5E and MXZA stock indices, while the rest of the stock indices are found statistically significant at all conventional levels. However, the innovations in the form of trend emerged statistically insignificant instead volatility factor is significant at all conventional levels with the coefficient of determination being about 87 percent. However, panel $\mathrm{B}$ of Table 9 presents the regression specification of CCMP stock index on the state variables establishing positive relationship with the rest of the stock indices, which hence is found statistically significant at all conventional levels, with the exception of UKX and FTSE Top 40 stock indices, wherein negative relationships are shown.
Response of CCMP INDEX to SX5E INDEX

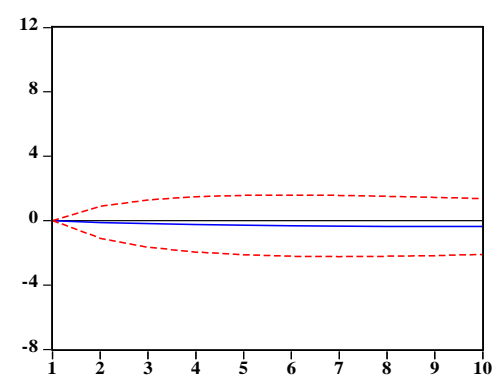

Response of CCMP INDEX to HSI INDEX

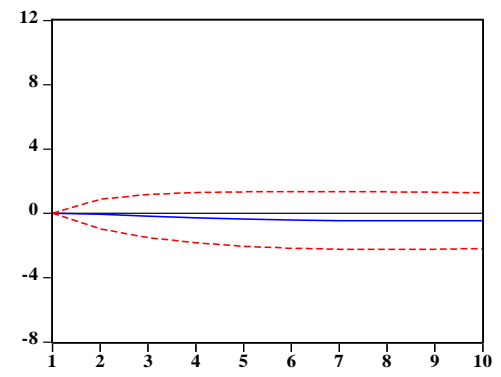

Response of CCMP INDEX to UKX INDEX

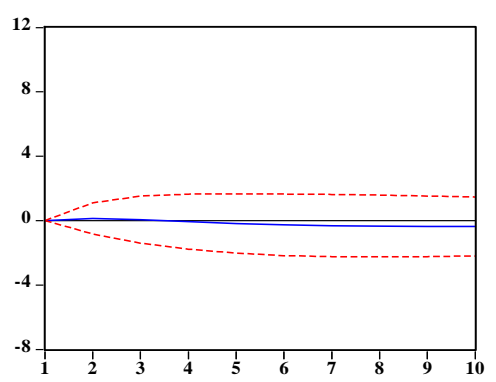

Response of CCMPINDEX to CNX-500 INDEX

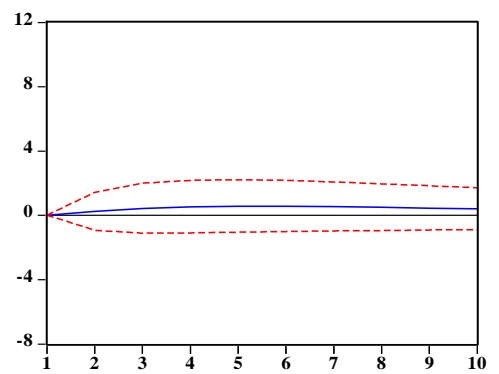

Response of CCMP INDEX to NKY INDEX

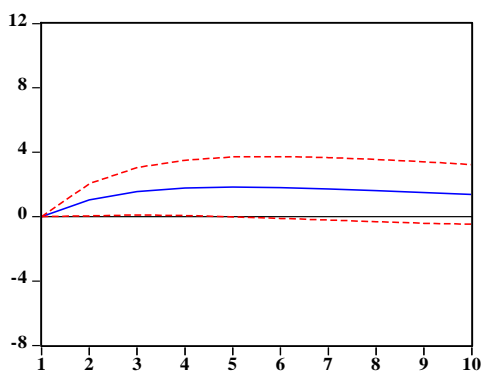

Response of CCMP INDEX to TA-100 INDEX

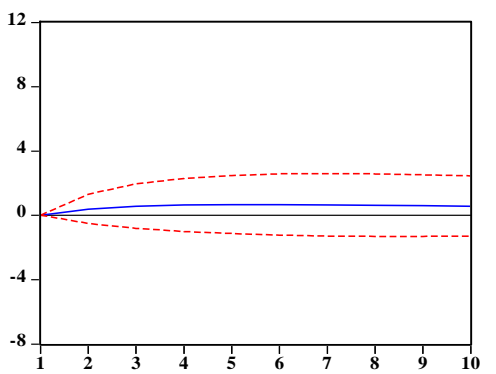

Response of CCMP INDEX to FTSE TOP-40 INDEX

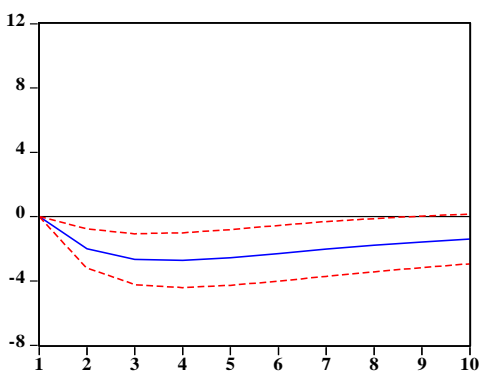

Response of CCM PINDEX to MXZA INDEX

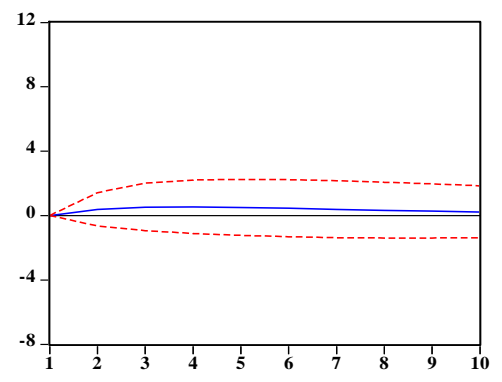

Fig. 5 GIRs of CCMP to one S.E shock in SX5E, UKX, NKY, HSI, CNX-500, TA-100, FTSE TOP-40 and MXZA 
Both the stock returns indices and the innovation factors are also statistically significant at all conventional levels with the coefficient of determination being 84 percent, respectively. Panel C of Table 9 depicts the regression specification of SX5E stock indices indicating that all the stock indices possess positive relationship and are statistically significant at all conventional levels with the exception of CCMP and NKY stock indices. However, FTSE Top 40 stock index shows negative relationship with SX5E stock index, with the coefficient of determination being 75 percent.

Panel D of Table 9 presents the regression specifications for UKX stock index for the rest of the state variables and reveals SPX, CCMP, SX5E, HSI, TA-100 stock indices, and the volatility $\left(\varepsilon_{t-1}^{2}\right)$ factor indicates positive relationship with UKX stock index and is statistically significant at all conventional levels with the coefficient of determination being 86 percent.
Response of SX5E INDEX to CCMP INDEX

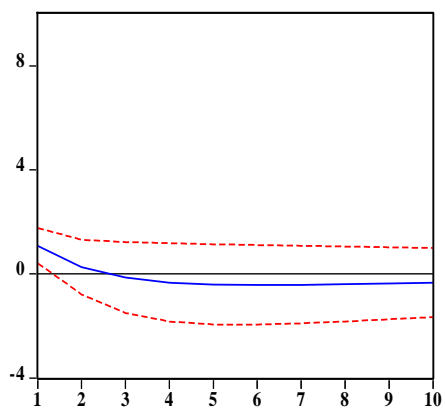

Response of SX5E INDEX to HSI INDEX

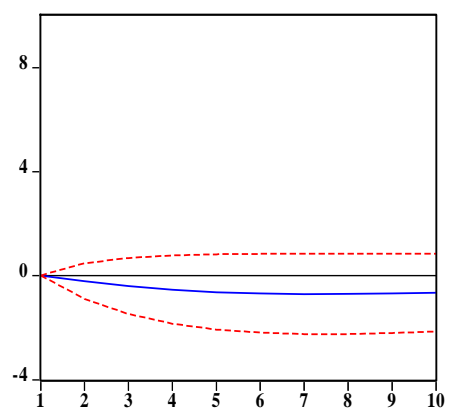

Response of SX5E INDEX to UKX INDEX

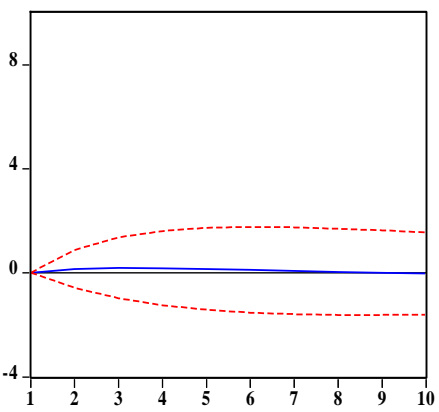

Response of SX5E INDEX to CNX-500 INDEX

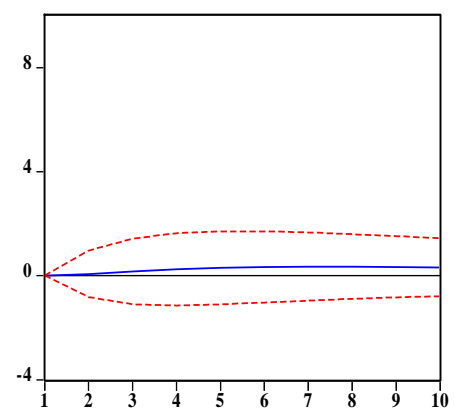

Response of SX5E INDEX to MXZA INDEX

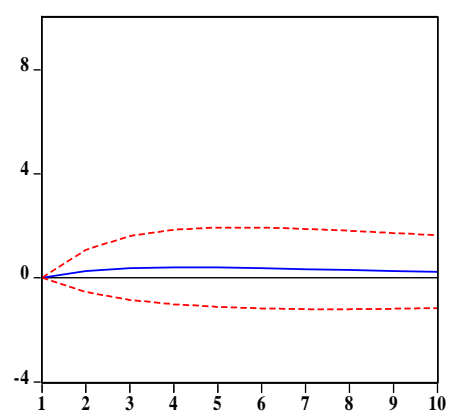

Response of SX5E INDEX to NKY INDEX

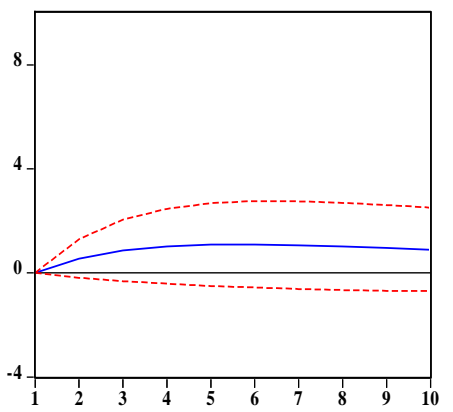

Response of SX5E INDEX to FTSE TOP-40 INDEX

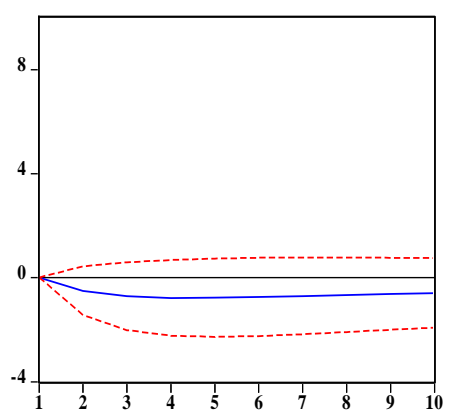

Fig. 6 GIRs of SX5E to one S.E shock in CCMP, UKX, NKY, HSI, CNX-500, FTSE TOP-40 and MXZA 
However, the rest of the indices are statistically insignificant with the exception of FTSE top-40 index establishing positive relationship with UKX index. Panel E of Table 9 presents the regression specification of NKY stock index regressed on the rest of the state variables and reveals CCMP, TA-100, FTSE Top 40 and MXZA stock indices showing positive relationship with NKY stock index with the coefficient of determination being 65 percent, and is found statistically significant at all conventional levels. However, the volatility $\left(\varepsilon_{t-1}^{2}\right)$ and the trend representing moving average $\left(\boldsymbol{h}_{t-1}\right)$ establishing positive relationship with NKY stock index are statistically significant at all conventional levels. Subsequently, UKX stock index confirms positive relationship with NKY stock index at five percent significance level, with the coefficient of determination being 65 percent.

Panel F of Table 9 presents the regression specification of HSI stock index on the state variables. CCMP, UKX, CNX 500, FTSE Top 40 and MXZA hold the positive relationships with HSI stock index with the exception of SPX stock index showing negative relationship mimicking the coefficient of determination of $75 \%$, which is statistically significant at all conventional levels. However, SX5E stock index holds positive relationship with HSI stock index and is statistically significant at ten percent level Panel G of Table 9 presents the regression specification of CNX 500 stock index regressed on the state variables. CCMP, SX5E, HSI, TA-100 and MXZA establish the positive relationships with CNX 500 , with the coefficient of determination being 79 percent, which is statistically significant at all conventional levels. However, SPX is showing negative relation-ship with CNX 500 stock index, with b coefficient being -1.39 . Successively, the $\varepsilon_{t-1}^{2}$ and $\boldsymbol{h}_{t-1}$ establish positive relationships with the CNX 500 stock index, which are statistically significant at all conventional levels. Panel H of Table 9 presents the regression specification of TA-100 stock index regressed on the state variables. SPX, SX5E, CNX 500 and MXZA stock indices hold positive relationships with TA-100 stock index, with the coefficient of determination being 65 percent, which are statistically significant at all conventional levels. However, UKX and FTSE Top 40 stock indices show negative relationship with TA-100 stock index and are statistically significant at all conventional levels. Successively the shows positive relationship with TA-100 stock index, which is statistically significant at all conventional levels. UKX and FTSE stock indices establish negative relationships with TA-100 stock index, which are statistically significant at all conventional levels, whereas HSI stock index holds positive relationship with TA-100 stock index, which is statistically significant at five percent level.

Panel I of Table 9 presents the regression specification of FTSE Top 40 stock index on the state variables. NIKY, HSI, TA-100 and MXZA hold positive relationships with FTSE Top 40 stock index, with the coefficient of determination being 96 percent and are statistically significant at all conventional levels. SPX, CCMP and CNX 500 stock indices possess negative relationships with FTSE Top 40 stock index and are statistically significant at all conventional levels. $\varepsilon_{t-1}^{2}$ reveals positive relationships with FTSE Top 40 stock index and is statistically significant at all conventional levels. Panel J of Table 9 presents the regression specification of MXZA stock index on the state variables. CCMP, CNX 500 and FTSE Top 40 stock indices establish positive relationships with MXZA stock index, with the coefficient of determination being 95 percent and is statistically significant at all conventional levels. However SX5E, UKX, NKY and HSI indices are having negative relation-ships with MXZA stock index and are statistically significant at all conventional levels. $\varepsilon_{t-1}^{2}$ and $\boldsymbol{h}_{t-1}$ reveals positive relationship with MXZA stock index and is statistically significant at one and five percent levels, respectively.

However, Table 10 presents regression specifications of time-varying beta employing GARCH(1,1) methodology for the subprime crisis sample period on the respective global stock indices. The specifications in Panel A Table 10 indicate that CCMP and UKX stock indices have positive relationship with the SPX stock index returns and are statistically significant at five and ten percent levels, respectively, with the coefficient of determination being 77 percent. How-ever, TA-100 stock index and $\boldsymbol{h}_{t-1}$ innovation factor representing trend establish negative relationships with SPX stock index and are statistically significant at one and five percent levels, respectively. Panel B of Table 10 presents the regression specification 

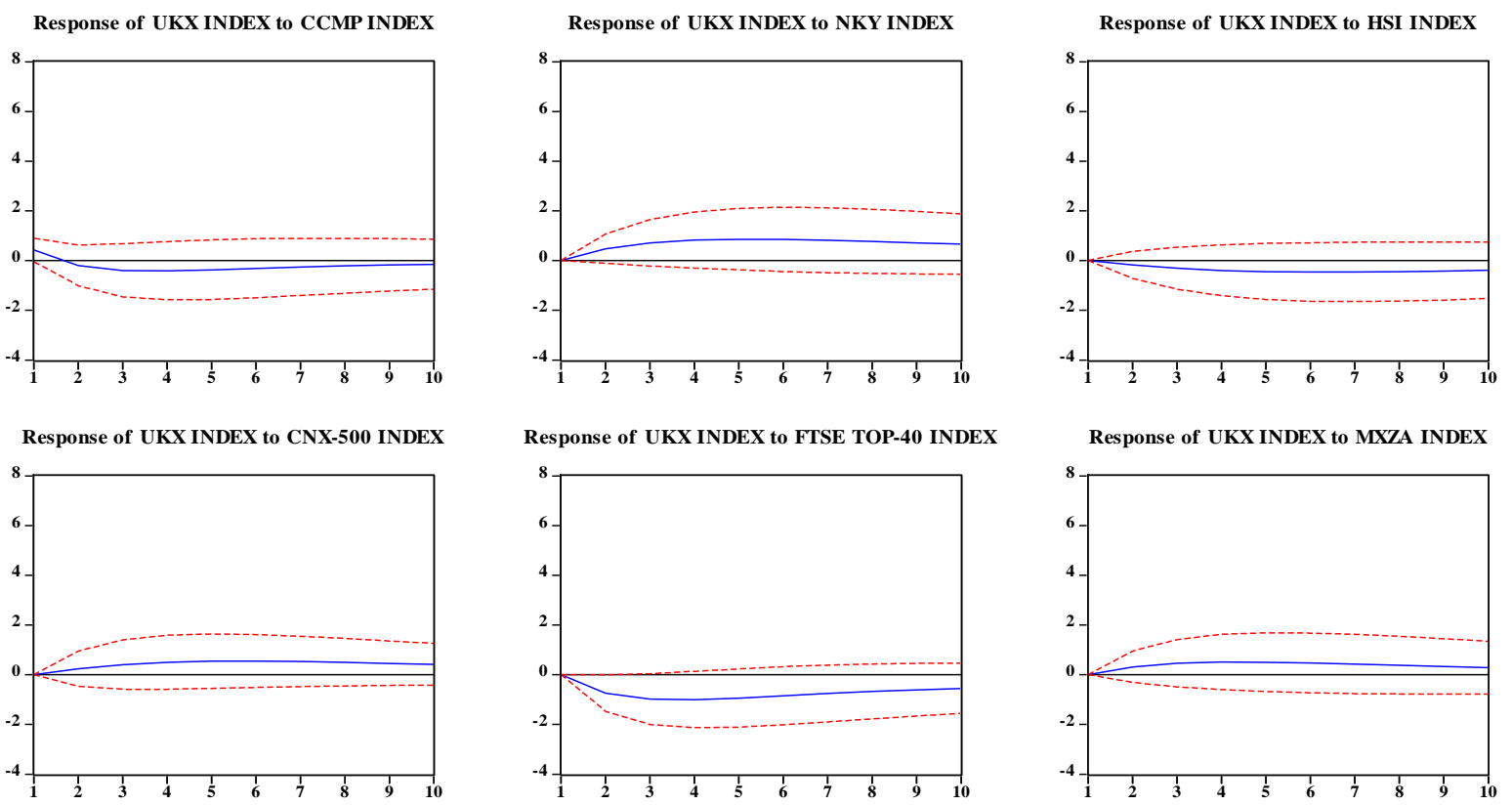

Fig. 7 GIRs of UKX to one S.E shock in CCMP, NKY, HSI, CNX-500, FTSE TOP-40 and MXZA

of CCMP stock index on state variables shows positive relationship of SPX stock index and negative relationship of NKY stock index and is statistically significant at five percent level, with the coefficient of determination being 65 percent. The rest of the stock returns indices and the innovation factors are likewise statistically insignificant. Panel $\mathrm{C}$ of Table 10 depicts the regression specification of SX5E stock index indicating that SPX, HSI, TA-100 stock indices hold positive relationships with SX5E and are statistically significant at all conventional levels, with the coefficient of determination being 75 percent. However, CCMP, CNX 500 and UKX stock indices establish negative relationships with SX5E stock index, with the coefficient of determination being 75 percent and are statistically significant at five, five, and ten percent levels, respectively.

Panel D of Table 10 presents the regression specification for UKX stock index on the rest of the state variables and reveals that SPX and HSI stock indices establish positive relationships with UKX stock index and are statistically significant at five percent level, respectively, with the coefficient of determination being 61 percent. However, SX5E stock index establishes negative relationship with UKX stock index and is statistically significant at five percent level. Panel E of Table 10 presents the regression specification of NKY stock index regressed on the rest of state variables and indicates that SPX stock index holds positive relationship with NKY stock index, with the coefficient of determination being 50 percent and is statistically significant at five percent level. However, CCMP stock index is having negative relationship with NKY stock index and is statistically significant at 5 percent level. Panel $\mathrm{F}$ of Table 10 presents the regression specification of HSI stock index on the state variables and indicates that CCMP, SX5E, CNX 500 and UKX stock indices are having positive relation-ships with HSI stock index, with the coefficient of determination being 70 percent and are statistically significant at ten, five, five, and one percent levels, respectively. However, SPX and TA-100 stock Indices hold negative relationships with HSI stock index and is statistically significant at all conventional levels. Panel G of Table 10 presents the regression specification of CNX 500 stock index regressed on the state variables. SPX, HSI, TA-100 stock indices establish positive relationships with CNX 500, and the coefficient of determination is 76 percent and are statistically significant at ten, ten, and one percent levels, respectively. However, CCMP stock index holds negative relationship with CNX 500 stock index, with b coefficient being -2.19 and is statistically significant at ten percent level. 

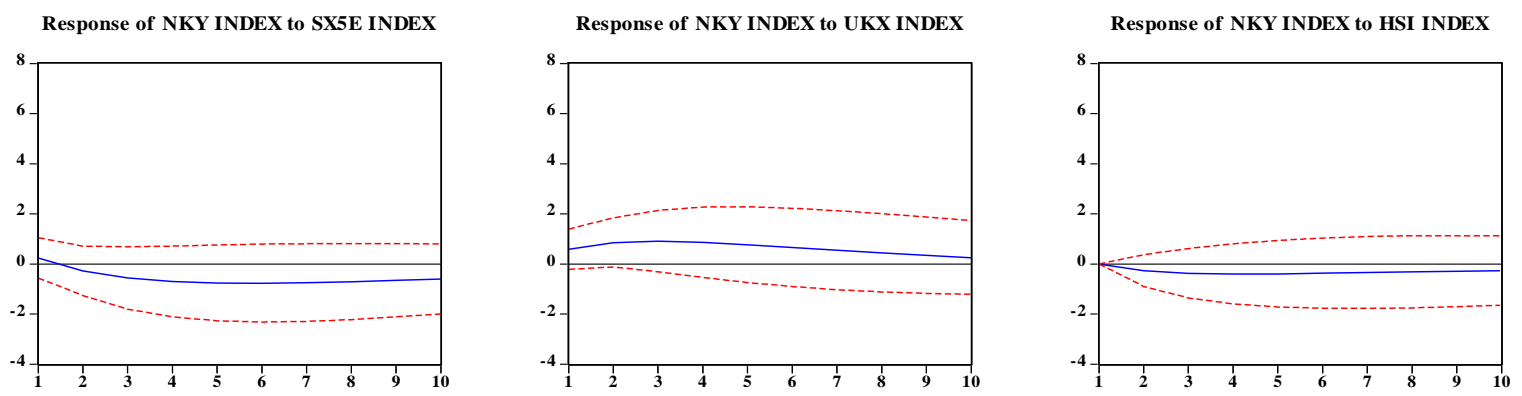

Response of NKY INDEX to CNX-500 INDEX
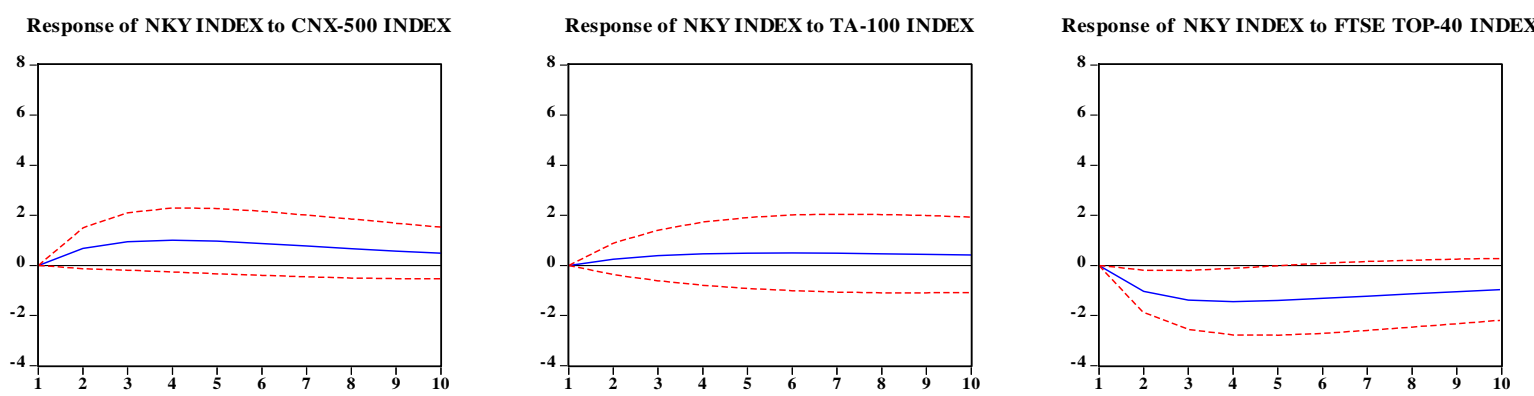

Response of NKY INDEX to MXZA INDEX

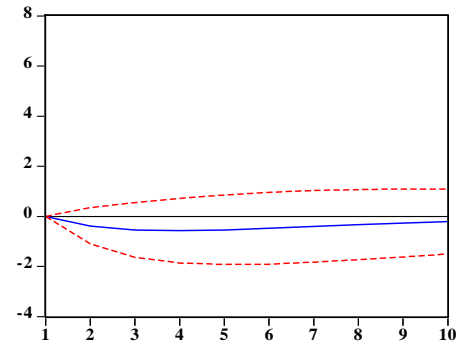

Fig. 8 GIRs of NKY to one S.E shock in SX5E, UKX, HSI, CNX-500, TA-100, FTSE TOP-40 and MXZA

Panel $\mathrm{H}$ of Table 10 presents the regression specification of TA-100 stock index regressed on the state variables. CCMP, CNX 500, SX5E stock indices show positive relationships with TA-100 stock index, with the coefficient of determination being 73 percent and are statistically significant at ten, one, and one percent levels, respectively. However, SPX and HIS indices have negative relationships with TA-100 stock index and are statistically significant at five and one percent levels, respectively. Panel I of Table 10 presents the regression specification of FTSE Top 40 stock index regressed on the state variables. All the variables are too insignificant to establish the relationship. Panel $\mathbf{J}$ of Table 10 presents the regression specification of MXZA stock index regressed on the state variables. FTSE Top 40 stock index establishes positive relationship with MXZA, the coefficient of determination being 75 percent and is statistically significant at five percent level. However, the rest of the variables are statistically insignificant. The successive empirical evidences revealed that the beta coefficient deviates with the variation in time and thus signifies and supports the proponents of persistence of time-varying global financial stock market inefficiency.

\section{Empirical interpretation}

The present study examines dynamic persistence and stock market linkages in the global financial stock market, for which the vector auto-regression model been employed. Panels A, B, C, and D of Table 1 present the descriptive statistics for the full sample period, pre-, during and post-subprime crisis periods, respectively, and subsequently implies that CNX 500 stock index is more prone due to extreme fluctuations in 
Response of HSI INDEX to CNX-500 INDEX

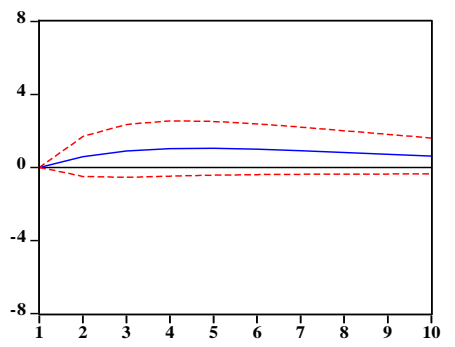

Response of HSI INDEX to TA-100 INDEX

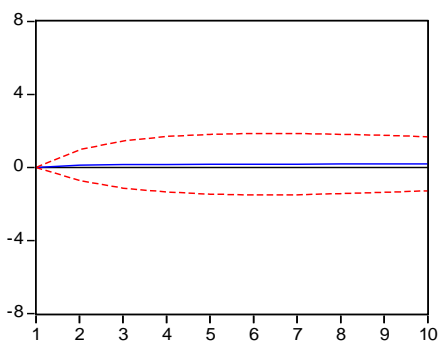

Response of HSI INDEX to FTSE TOP-40 INDEX

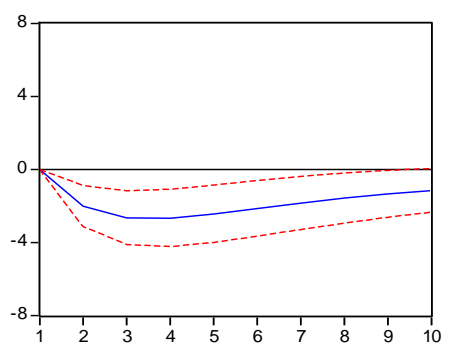

Fig. 9 GIRs of HSI to one S.E shock in CNX-500, TA-100 and FTSE TOP-40

Response of CNX-500 INDEX to TA-100 INDEX

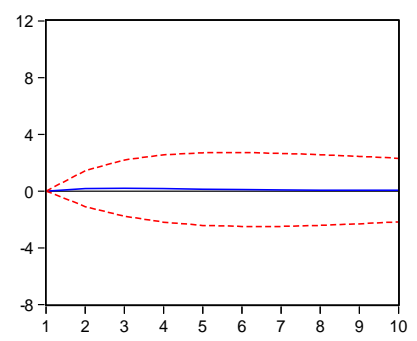

Response of CNX-500 INDEX to FTSE TOP-40 INDEX

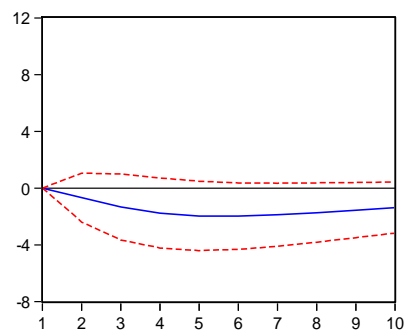

Response of CNX-500 INDEX to MXZA INDEX

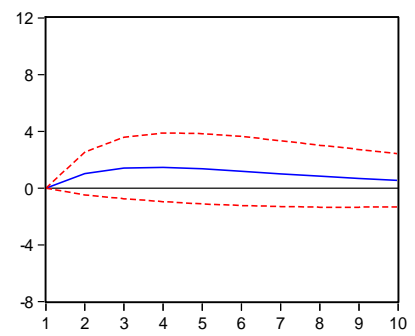

Fig. 10 GIRs of CNX-500 to one S.E shock in TA-100, FTSE TOP-40 and MXZA

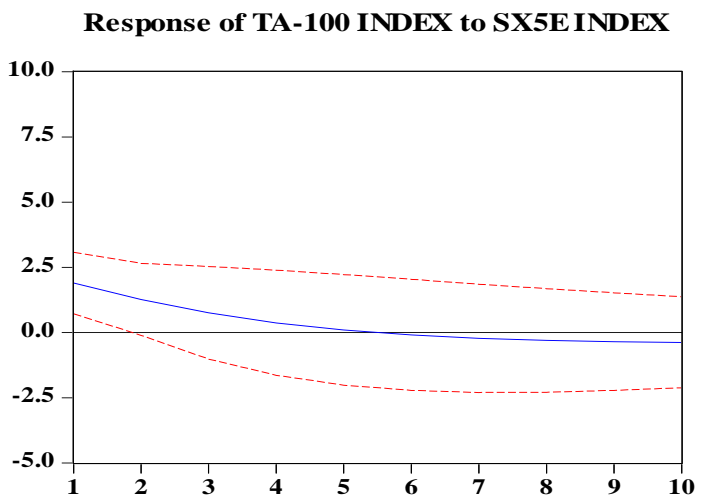

Response of TA-100 INDEX to FTSE TOP-40 INDEX

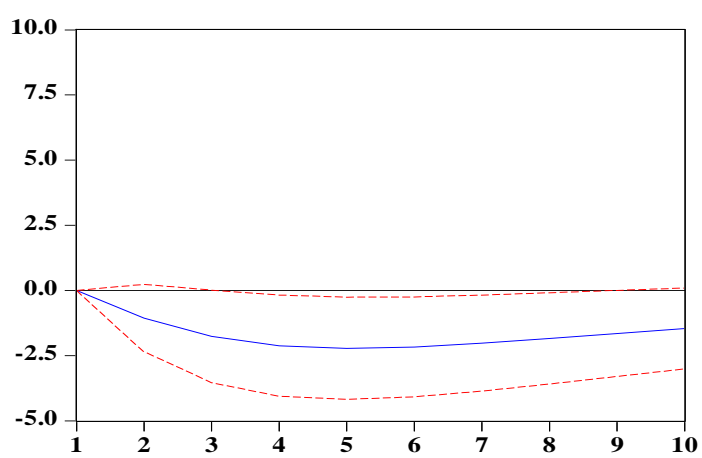

Response of TA-100 INDEX to NKY INDEX

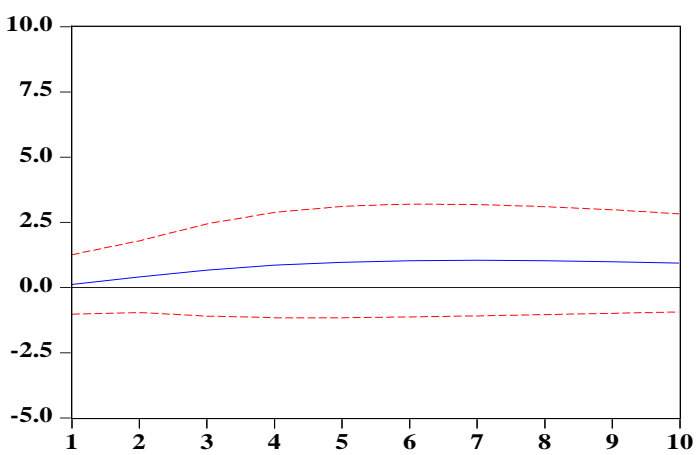

Response of TA-100 INDEX to MXZA INDEX

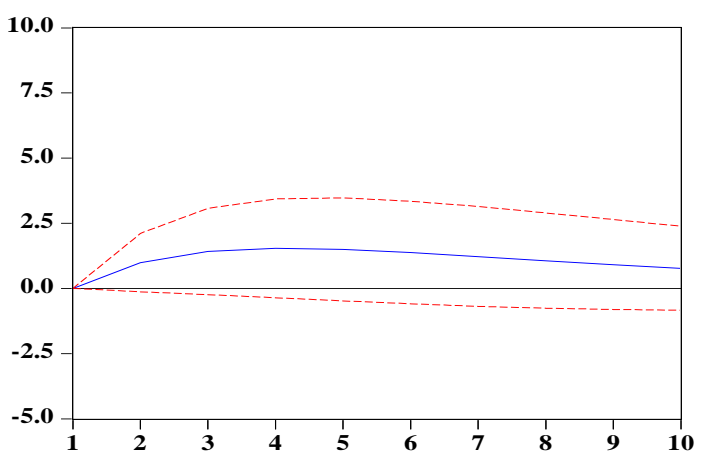

Fig. 11 GIRs of TA-100 to one S.E shock in SX5E, NKY, FTSE TOP-40 and MXZA 

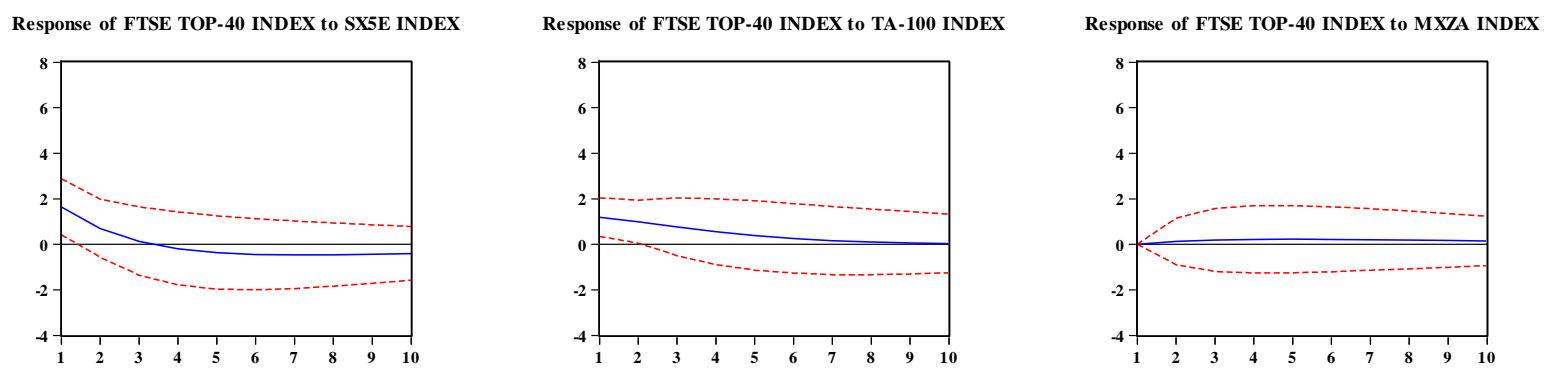

Fig. 12 GIRs of FTSE TOP-40 to one S.E shock in SX5E, TA-100 and MXZA
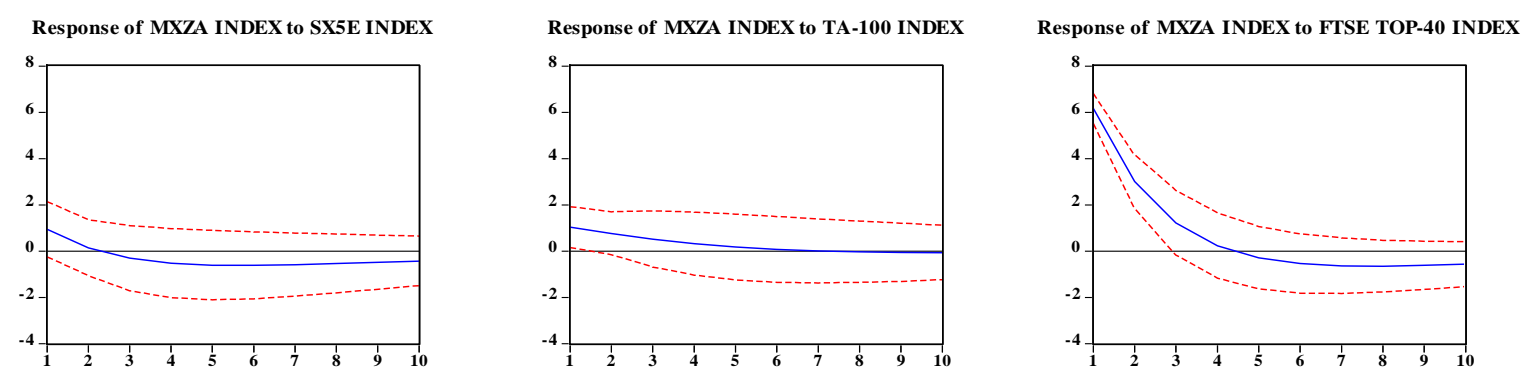

Fig. 13 GIRs of MXZA to one S.E shock in SX5E, TA-100 and FTSE TOP-40

mean returns $(6.86,7.83,-12.89$, and 10.56) with high standard deviations (26.42, 23.33, 38.62 and 26.75). Hence, the Indian stock market is considered to be more risky to hold the stocks in the portfolio. Thus, the stocks have to choose from the different sets of the baskets to form the unique portfolio with diversifiable risk for the investment purpose. However, the UKX stock indices has less mean returns compared to the rest of the stock indices with less variations in returns across the periods. The period of subprime crisis led to downturn in the respective stock indices representing the world economy and successively incurring negative returns during the period. The whole process is the part and parcel of the business cycle which comprises certain degree of inefficiency that provides the arbitrageur with the opportunity to create the arbitrage position through international diversification, and thus to maximize the profit for the short-period of time or until such time as the new set of information reflects into the current stock price to form the state of price equilibrium. However, the evidences of high correlation and co-variance further support the persistence of dynamics with the global stock market linkages. The VAR specification revealed that the lagged prices of global stock indices were able to predict the future price of a specific stock index in the presence of its own lagged price. The VAR specifications reveal that the information set about global stock market linkages can predict approximately 70 percent of returns as well as variations in future returns of the respective indices. However, the subprime crisis period entails uneven fluctuations in the coefficient of determination because of which the NKY stock index experienced negative coefficient of determination ( -12 percent), contrasting with the coefficient of determination for SX5E stock index being 91 percent. Hence, such uneven fluctuations in stock returns has been in turn attributed to the market dynamics and the degree of global stock market linkages.

The Granger causality test unveils the dynamic interactions between stock indices, and hence Table 7 presents the evidences for dynamic linkages with NKY stock index and SPX stock index and follows a bidirectional causality that can bring about causality either way; consequently, NKY and CCMP stock indices follow the bidirectional causality, and NKY stock index and SX5E stock index follow bidirectional causality, respectively. CNX 500 and HSI stock indices granger cause each other; FTSE Top 40 and CCMP stock indices granger cause each other; and simultaneously all indices collectively granger 
Table 8 Variance decomposition analysis of global stock returns indices

\begin{tabular}{|c|c|c|c|c|c|c|c|c|c|c|}
\hline \multicolumn{11}{|l|}{ Panel A } \\
\hline \multirow[t]{2}{*}{ Time lag } & \multicolumn{10}{|c|}{ Variance decomposition of SPX } \\
\hline & SPX & CCMP & SX5E & UKX & NKY & HSI & CNX 500 & TA-100 & FTSE Top 40 & MXZA \\
\hline 1 & 100.0000 & 0.000000 & 0.000000 & 00.000000 & $\begin{array}{ll}0 & 0.000000\end{array}$ & 0.000000 & 0.000000 & 0.000000 & 0.000000 & 0.000000 \\
\hline 2 & 98.04892 & 0.341464 & 0.008220 & $20 \quad 0.004489$ & $9 \quad 0.218372$ & $2 \quad 0.039845$ & 0.008524 & 0.004715 & 1.291143 & 0.034310 \\
\hline 3 & 95.64400 & 0.649094 & 0.019500 & 0.032745 & $5 \quad 0.571163$ & 30.129891 & 0.028334 & 0.011138 & 2.835448 & 0.078692 \\
\hline 4 & 93.53225 & 0.829669 & 0.030985 & $35 \quad 0.092456$ & $6 \quad 0.963516$ & $5 \quad 0.254100$ & 0.054711 & 0.018531 & 4.106415 & 0.117363 \\
\hline 5 & 91.83311 & 0.914881 & 0.042129 & $29 \quad 0.177339$ & $9 \quad 1.348692$ & 20.394841 & 0.082547 & 0.027236 & 5.032900 & 0.146323 \\
\hline 6 & 90.4930 & $\begin{array}{ll}00 & 0.94589\end{array}$ & $91 \quad 0.053027$ & $27 \quad 0.275985$ & $5 \quad 1.705401$ & 0.538462 & 0.108352 & 0.037654 & 5.676077 & 0.166148 \\
\hline 7 & 89.4329 & $93 \quad 0.95021$ & $14 \quad 0.063842$ & $12 \quad 0.377835$ & $5 \quad 2.025234$ & $4 \quad 0.676133$ & 0.130383 & 0.049983 & 6.114673 & 0.178776 \\
\hline 8 & 88.5858 & $82 \quad 0.94301$ & $16 \quad 0.07465$ & $\begin{array}{ll}50 & 0.475412\end{array}$ & $2 \quad 2.306328$ & 30.802989 & 0.148158 & 0.064169 & 6.413233 & 0.186226 \\
\hline 9 & 87.9012 & $22 \quad 0.93185$ & $55 \quad 0.085435$ & $\begin{array}{ll}35 & 0.564399\end{array}$ & $9 \quad 2.550114$ & $4 \quad 0.916916$ & 0.161920 & 0.079946 & 6.618020 & 0.190178 \\
\hline 10 & 87.3422 & $26 \quad 0.92020$ & $09 \quad 0.096105$ & $55 \quad 0.642917$ & $7 \quad 2.759584$ & 1.017521 & 0.172245 & 0.096906 & 6.760369 & 0.191885 \\
\hline Panel B & & & & & & & & & & \\
\hline Time lag & g Variance & e decomposit & ition of $\mathrm{CCM}$ & & & & & & & \\
\hline & SPX & CCMP & SX5E & UKX & NKY & HSI & CNX 500 & TA-100 & FTSE Top 40 & MXZA \\
\hline 1 & 67.6322 & $33 \quad 32.36777$ & $\begin{array}{ll}7 & 0.000000\end{array}$ & $\begin{array}{ll}0 & 0.000000\end{array}$ & 0.000000 & 0.000000 & 0.000000 & 0.000000 & 0.000000 & 0.000000 \\
\hline 2 & 70.1718 & $34 \quad 26.98621$ & $1 \quad 0.006831$ & $1 \quad 0.008877$ & 0.569126 & 0.001425 & 0.033275 & 0.080423 & 2.066273 & 0.075718 \\
\hline 3 & 70.2813 & $35 \quad 23.12946$ & $\begin{array}{ll}6 & 0.020365\end{array}$ & $5 \quad 0.008438$ & 1.472506 & 0.012834 & 0.104664 & 0.200039 & 4.596982 & 0.173358 \\
\hline 4 & 69.60381 & $31 \quad 20.47871$ & $1 \quad 0.039057$ & $7 \quad 0.008860$ & 2.417061 & 0.038794 & 0.193587 & 0.322182 & 6.643110 & 0.254832 \\
\hline 5 & 68.8195 & $4 \quad 18.63990$ & $\begin{array}{ll}0 & 0.061936\end{array}$ & $\begin{array}{ll}6 & 0.018346\end{array}$ & 3.272555 & 0.077210 & 0.281969 & 0.434286 & 8.082030 & 0.312228 \\
\hline 6 & 68.13757 & $\begin{array}{ll}7 & 17.33031\end{array}$ & $1 \quad 0.088128$ & $\begin{array}{ll}8 & 0.037720\end{array}$ & 3.999733 & 0.123439 & 0.359629 & 0.533863 & 9.040689 & 0.348922 \\
\hline 7 & 67.59348 & $18 \quad 16.37058$ & $8 \quad 0.116648$ & $\begin{array}{ll}8 & 0.064160\end{array}$ & 4.598705 & 0.173049 & 0.422806 & 0.621574 & 9.668391 & 0.370606 \\
\hline 8 & 67.17112 & $2 \quad 15.64909$ & $9 \quad 0.146418$ & $8 \quad 0.094263$ & 5.083960 & 0.222768 & 0.471554 & 0.698756 & 10.07978 & 0.382295 \\
\hline 9 & 66.84467 & $\begin{array}{ll}77 & 15.09513\end{array}$ & $\begin{array}{ll}3 & 0.176373\end{array}$ & $\begin{array}{ll}3 & 0.125315\end{array}$ & 5.473604 & 0.270513 & 0.507718 & 0.766691 & 10.35229 & 0.387697 \\
\hline 10 & 66.59095 & $5 \quad 14.66257$ & $7 \quad 0.205575$ & $\begin{array}{ll}5 & 0.155539\end{array}$ & 5.785031 & 0.315118 & 0.533710 & 0.826468 & 10.53570 & 0.389338 \\
\hline Panel C & & & & & & & & & & \\
\hline Time & Variance de & ecomposition & of SX5E & & & & & & & \\
\hline & SPX & CCMP & SX5E & UKX & NKY & HSI & CNX 500 & TA-100 & FTSE Top 40 & MXZA \\
\hline 1 & 65.78757 & 1.570325 & 32.64211 & 0.000000 & 0.000000 & 0.000000 & 0.000000 & 0.000000 & 0.000000 & 0.000000 \\
\hline 2 & 67.53340 & 0.979820 & 30.93347 & 0.016821 & 0.237451 & 0.035915 & 0.003259 & 0.001886 & 0.202945 & 0.055033 \\
\hline 3 & 68.75275 & 0.765076 & 29.07786 & 0.034425 & 0.629490 & 0.125122 & 0.017487 & 0.002940 & 0.467132 & 0.127720 \\
\hline 4 & 69.65141 & 0.706473 & 27.32025 & 0.046026 & 1.068442 & 0.257126 & 0.044277 & 0.003099 & 0.709357 & 0.193545 \\
\hline 5 & 70.33061 & 0.707946 & 25.76061 & 0.051555 & 1.495432 & 0.414456 & 0.080311 & 0.002907 & 0.910553 & 0.245616 \\
\hline 6 & 70.84740 & 0.729540 & 24.42595 & 0.052800 & 1.882540 & 0.580644 & 0.120743 & 0.002685 & 1.073611 & 0.284085 \\
\hline 7 & 71.23969 & 0.755385 & 23.30843 & 0.051659 & 2.219704 & 0.743405 & 0.161317 & 0.002525 & 1.206544 & 0.311345 \\
\hline 8 & 71.53563 & 0.779617 & 22.38526 & 0.049631 & 2.506376 & 0.894998 & 0.199112 & 0.002414 & 1.316869 & 0.330088 \\
\hline 9 & 71.75718 & 0.800411 & 21.62892 & 0.047752 & 2.746563 & 1.031401 & 0.232519 & 0.002325 & 1.410292 & 0.342637 \\
\hline 10 & 71.92161 & 0.817518 & 21.01218 & 0.046664 & 2.946051 & 1.151209 & 0.260931 & 0.002256 & 1.490791 & 0.350799 \\
\hline D & & & & & & & & & & \\
\hline le & 1a! & ecomposition & n of UKX & & & & & & & \\
\hline
\end{tabular}




\begin{tabular}{|c|c|c|c|c|c|c|c|c|c|c|}
\hline \multicolumn{11}{|c|}{ Table 8 continued } \\
\hline & SPX & CCMP & SX5E & UKX & NKY & HSI & CNX 500 & TA-100 & FTSE Top 40 & MXZA \\
\hline 1 & 73.61026 & 0.406592 & 7.517527 & 18.46562 & 0.000000 & 0.000000 & 0.000000 & 0.000000 & 0.000000 & 0.000000 \\
\hline 2 & 73.06108 & 0.291514 & 7.156142 & 18.24384 & 0.290002 & 0.039634 & 0.074503 & 0.004058 & 0.711081 & 0.128148 \\
\hline 3 & 72.42686 & 0.381313 & 6.739760 & 17.52955 & 0.735660 & 0.126064 & 0.219573 & 0.017172 & 1.514982 & 0.309056 \\
\hline 4 & 71.97700 & 0.472127 & 6.344397 & 16.69137 & 1.206392 & 0.241214 & 0.397866 & 0.038185 & 2.149270 & 0.482176 \\
\hline 5 & 71.70906 & 0.528791 & 5.995222 & 15.88804 & 1.644056 & 0.366818 & 0.579772 & 0.063173 & 2.599493 & 0.625571 \\
\hline 6 & 71.56735 & 0.557912 & 5.698053 & 15.17848 & 2.027472 & 0.489729 & 0.747071 & 0.088201 & 2.910344 & 0.735382 \\
\hline 7 & 71.50258 & 0.570627 & 5.451023 & 14.57678 & 2.352967 & 0.602342 & 0.891032 & 0.110523 & 3.126983 & 0.815139 \\
\hline 8 & 71.48118 & 0.574821 & 5.249092 & 14.07792 & 2.624512 & 0.701299 & 1.009305 & 0.128743 & 3.282463 & 0.870663 \\
\hline 9 & 71.48238 & 0.575029 & 5.086071 & 13.66973 & 2.848877 & 0.785953 & 1.103199 & 0.142517 & 3.398436 & 0.907814 \\
\hline 10 & 71.49391 & 0.573618 & 4.955666 & 13.33835 & 3.033327 & 0.857154 & 1.175765 & 0.152174 & 3.488423 & 0.931613 \\
\hline
\end{tabular}

\section{Panel E}

\begin{tabular}{lllllllllll}
\hline $\begin{array}{l}\text { Time } \\
\text { lag }\end{array}$ & \multicolumn{2}{l}{ Variance decomposition of NKY } \\
\cline { 2 - 11 } & SPX & CCMP & SX5E & UKX & NKY & HSI & CNX 500 & TA-100 & FTSE Top 40 & MXZA \\
\hline 1 & 16.96514 & 24.70777 & 0.094046 & 0.568915 & 57.66413 & 0.000000 & 0.000000 & 0.000000 & 0.000000 & 0.000000 \\
2 & 17.43587 & 19.01862 & 0.133937 & 1.045225 & 60.57524 & 0.070152 & 0.449353 & 0.061946 & 1.063830 & 0.145828 \\
3 & 18.02662 & 15.46077 & 0.338051 & 1.396750 & 60.88162 & 0.158691 & 1.008454 & 0.158787 & 2.240344 & 0.329909 \\
4 & 18.75082 & 13.22339 & 0.593123 & 1.624582 & 60.16496 & 0.235134 & 1.476020 & 0.263741 & 3.186027 & 0.482195 \\
5 & 19.54073 & 11.77055 & 0.846200 & 1.758030 & 59.11893 & 0.294361 & 1.815997 & 0.364927 & 3.902020 & 0.588256 \\
6 & 20.33069 & 10.79241 & 1.075171 & 1.825430 & 58.03093 & 0.339146 & 2.046480 & 0.457487 & 4.448155 & 0.654103 \\
7 & 21.07652 & 10.11158 & 1.272459 & 1.849044 & 57.01554 & 0.373476 & 2.195867 & 0.539816 & 4.875169 & 0.690530 \\
8 & 21.75424 & 9.623794 & 1.437312 & 1.845370 & 56.11314 & 0.400638 & 2.289123 & 0.611867 & 5.217046 & 0.707466 \\
9 & 22.35438 & 9.265572 & 1.572132 & 1.826246 & 55.33161 & 0.422944 & 2.344971 & 0.674327 & 5.495357 & 0.712468 \\
10 & 22.87648 & 8.996939 & 1.680625 & 1.799851 & 54.66473 & 0.441906 & 2.376505 & 0.728190 & 5.724023 & 0.710747 \\
\hline
\end{tabular}

Panel F

\begin{tabular}{|c|c|c|c|c|c|c|c|c|c|c|}
\hline \multirow{2}{*}{$\begin{array}{l}\text { Time } \\
\text { lag }\end{array}$} & \multicolumn{10}{|c|}{ Variance decomposition of HSI } \\
\hline & SPX & CCMP & SX5E & UKX & NKY & HSI & CNX 500 & TA-100 & $\begin{array}{l}\text { FTSE Top } \\
40\end{array}$ & MXZA \\
\hline 1 & 32.71093 & 18.09624 & 7.492229 & 8.947909 & 1.045830 & 31.70687 & 0.000000 & 0.000000 & 0.000000 & 0.000000 \\
\hline 2 & 30.14245 & 15.05612 & 6.818313 & 10.54863 & 2.366743 & 32.37311 & 0.210574 & 0.008318 & 2.474195 & 0.001535 \\
\hline 3 & 27.85436 & 13.21367 & 6.146552 & 11.29286 & 3.652884 & 31.83626 & 0.561877 & 0.017933 & 5.420723 & 0.002885 \\
\hline 4 & 26.14834 & 12.11750 & 5.610455 & 11.57431 & 4.759715 & 31.01798 & 0.940685 & 0.026782 & 7.800654 & 0.003577 \\
\hline 5 & 24.94356 & 11.46177 & 5.215736 & 11.63503 & 5.665469 & 30.24848 & 1.287386 & 0.035240 & 9.503551 & 0.003776 \\
\hline 6 & 24.10139 & 11.06560 & 4.935892 & 11.59911 & 6.388473 & 29.61163 & 1.578809 & 0.043907 & 10.67147 & 0.003722 \\
\hline 7 & 23.50899 & 10.82350 & 4.742541 & 11.52650 & 6.956907 & 29.10886 & 1.811281 & 0.053154 & 11.46468 & 0.003594 \\
\hline 8 & 23.08732 & 10.67341 & 4.612269 & 11.44522 & 7.399022 & 28.71940 & 1.990220 & 0.063104 & 12.00654 & 0.003500 \\
\hline 9 & 22.78333 & 10.57863 & 4.527076 & 11.36774 & 7.740044 & 28.41996 & 2.124399 & 0.073692 & 12.38164 & 0.003487 \\
\hline 10 & 22.56159 & 10.51744 & 4.473488 & 11.29897 & 8.001350 & 28.19030 & 2.223001 & 0.084727 & 12.64557 & 0.003566 \\
\hline
\end{tabular}

Panel G

\begin{tabular}{lllllllllll}
\hline Time & \multicolumn{2}{l}{ Variance decomposition of CNX 500 } \\
\cline { 2 - 12 } & SPX & CCMP & SX5E & UKX & NKY & HSI & CNX 500 & TA-100 & FTSE Top 40 & MXZA \\
\hline 1 & 13.45665 & 25.12100 & 6.795504 & 4.578124 & 0.962687 & 4.923727 & 44.16231 & 0.000000 & 0.000000 & 0.000000 \\
\hline
\end{tabular}




\begin{tabular}{lllllllllll}
\hline \multicolumn{2}{l}{ Table 8 continued } \\
\hline 2 & 13.92287 & 24.52282 & 6.663013 & 5.859346 & 1.184747 & 7.255968 & 40.21330 & 0.006458 & 0.115139 & 0.256348 \\
3 & 13.78744 & 23.81123 & 6.360717 & 6.901708 & 1.425905 & 9.116980 & 37.52765 & 0.012648 & 0.455732 & 0.599993 \\
4 & 13.39247 & 23.19329 & 6.025630 & 7.675047 & 1.664263 & 10.47910 & 35.68472 & 0.016215 & 0.962248 & 0.907016 \\
5 & 12.93674 & 22.72055 & 5.725077 & 8.211339 & 1.884536 & 11.43200 & 34.40529 & 0.017735 & 1.526439 & 1.140289 \\
6 & 12.51519 & 22.38329 & 5.482367 & 8.564661 & 2.078280 & 12.08574 & 33.50707 & 0.018200 & 2.063304 & 1.301888 \\
7 & 12.16272 & 22.15350 & 5.298306 & 8.787833 & 2.242416 & 12.53293 & 32.86949 & 0.018269 & 2.527749 & 1.406782 \\
8 & 11.88446 & 22.00215 & 5.164509 & 8.923381 & 2.377414 & 12.84119 & 32.41165 & 0.018262 & 2.905822 & 1.471158 \\
9 & 11.67298 & 21.90506 & 5.070275 & 9.002270 & 2.485784 & 13.05667 & 32.07878 & 0.018313 & 3.201477 & 1.508394 \\
10 & 11.51686 & 21.84401 & 5.005608 & 9.045710 & 2.570994 & 13.20986 & 31.83364 & 0.018484 & 3.426510 & 1.528331 \\
\hline
\end{tabular}

Panel H

\begin{tabular}{lllllllllll}
\hline \multirow{2}{*}{$\begin{array}{l}\text { Time } \\
\text { lag }\end{array}$} & \multicolumn{2}{l}{ Variance decomposition of TA-100 } \\
\cline { 2 - 11 } & SPX & CCMP & SX5E & UKX & NKY & HSI & CNX 500 & TA-100 & FTSE Top 40 & MXZA \\
\hline 1 & 38.40727 & 7.512423 & 2.542685 & 2.055430 & 0.009163 & 3.835939 & 13.86621 & 31.77087 & 0.000000 & 0.000000 \\
2 & 38.46776 & 7.250252 & 2.227114 & 2.447698 & 0.077518 & 4.774579 & 11.07030 & 32.77625 & 0.487276 & 0.421254 \\
3 & 37.81110 & 7.093384 & 1.942153 & 2.667890 & 0.210603 & 5.279272 & 9.455852 & 33.09126 & 1.437303 & 1.011193 \\
4 & 36.94307 & 7.042087 & 1.723278 & 2.755661 & 0.395086 & 5.486379 & 8.482878 & 33.03615 & 2.565010 & 1.570393 \\
5 & 36.09923 & 7.069347 & 1.571749 & 2.760357 & 0.610222 & 5.522862 & 7.869937 & 32.81046 & 3.657405 & 2.028435 \\
6 & 35.36787 & 7.145151 & 1.475918 & 2.721971 & 0.836412 & 5.475509 & 7.469068 & 32.52613 & 4.606300 & 2.375672 \\
7 & 34.76801 & 7.244159 & 1.421679 & 2.666918 & 1.058575 & 5.395203 & 7.199041 & 32.24069 & 5.379509 & 2.626215 \\
8 & 34.29028 & 7.347862 & 1.396534 & 2.610197 & 1.266651 & 5.308607 & 7.012755 & 31.98070 & 5.985911 & 2.800502 \\
9 & 33.91622 & 7.444490 & 1.390673 & 2.559048 & 1.454887 & 5.228095 & 6.881524 & 31.75597 & 6.451035 & 2.918056 \\
10 & 33.62634 & 7.527851 & 1.396868 & 2.516102 & 1.620782 & 5.158336 & 6.787237 & 31.56782 & 6.803633 & 2.995032 \\
\hline
\end{tabular}

Panel I

\begin{tabular}{|c|c|c|c|c|c|c|c|c|c|c|}
\hline \multirow{2}{*}{$\begin{array}{l}\text { Time } \\
\text { lag }\end{array}$} & \multicolumn{10}{|c|}{ Variance decomposition of FTSE Top 40} \\
\hline & SPX & CCMP & SX5E & UKX & NKY & HSI & CNX 500 & TA-100 & FTSE Top 40 & MXZA \\
\hline 1 & 12.90531 & 17.13499 & 2.290206 & 10.26097 & 10.14308 & 4.646870 & 9.221026 & 1.199559 & 32.19799 & 0.000000 \\
\hline 2 & 12.57058 & 14.82438 & 1.838968 & 14.88553 & 12.00001 & 5.837548 & 10.10479 & 1.381104 & 26.54827 & 0.008832 \\
\hline 3 & 11.98471 & 13.27865 & 1.555819 & 18.46810 & 13.13877 & 6.649256 & 10.64012 & 1.441781 & 22.81865 & 0.024138 \\
\hline 4 & 11.38934 & 12.26929 & 1.420878 & 20.93502 & 13.77344 & 7.169221 & 10.96023 & 1.434982 & 20.60573 & 0.041867 \\
\hline 5 & 10.88308 & 11.61164 & 1.382802 & 22.52345 & 14.10776 & 7.502093 & 11.16166 & 1.401637 & 19.36639 & 0.059475 \\
\hline 6 & 10.48546 & 11.18400 & 1.397544 & 23.50323 & 14.27621 & 7.723114 & 11.29752 & 1.363656 & 18.69374 & 0.075525 \\
\hline 7 & 10.18541 & 10.90885 & 1.436214 & 24.08666 & 14.35605 & 7.877847 & 11.39405 & 1.330119 & 18.33552 & 0.089285 \\
\hline 8 & 9.964196 & 10.73547 & 1.482242 & 24.42101 & 14.38933 & 7.992114 & 11.46426 & 1.303499 & 18.14739 & 0.100492 \\
\hline 9 & 9.803830 & 10.62967 & 1.527081 & 24.60292 & 14.39851 & 8.080306 & 11.51525 & 1.283461 & 18.04977 & 0.109204 \\
\hline 10 & 9.689430 & 10.56803 & 1.566896 & 24.69389 & 14.39555 & 8.150548 & 11.55161 & 1.268767 & 17.99959 & 0.115681 \\
\hline \multicolumn{11}{|c|}{ Panel J } \\
\hline \multirow{2}{*}{$\begin{array}{l}\text { Time } \\
\text { lag }\end{array}$} & \multicolumn{10}{|c|}{ Variance decomposition Of MXZA } \\
\hline & SPX & CCMP & SX5E & UKX & NKY & HSI & CNX 500 & TA-100 & FTSE Top 40 & $\overline{\text { MXZA }}$ \\
\hline 1 & 11.06872 & 15.11506 & 0.844507 & 8.135366 & 8.556059 & 3.555523 & 11.97412 & 1.017488 & 36.24326 & 3.489893 \\
\hline 2 & 10.63361 & 13.67095 & 0.587769 & 12.04615 & 9.649999 & 4.532413 & 13.31524 & 1.072601 & 30.60929 & 3.881973 \\
\hline 3 & 10.03232 & 12.68840 & 0.549604 & 15.17248 & 10.23760 & 5.277450 & 14.15829 & 1.054453 & 26.72407 & 4.105336 \\
\hline 4 & 9.452503 & 12.03772 & 0.637042 & 17.37694 & 10.49694 & 5.820727 & 14.65767 & 1.008125 & 24.29342 & 4.218919 \\
\hline
\end{tabular}




\begin{tabular}{|c|c|c|c|c|c|c|c|c|c|c|}
\hline \multicolumn{11}{|c|}{ Table 8 continued } \\
\hline 5 & 8.972649 & 11.61832 & 0.773684 & 18.81449 & 10.57723 & 6.217823 & 14.94767 & 0.960323 & 22.84779 & 4.270011 \\
\hline 6 & 8.607525 & 11.35863 & 0.915034 & 19.70221 & 10.57135 & 6.515533 & 15.11541 & 0.921539 & 22.00507 & 4.287696 \\
\hline 7 & 8.345322 & 11.20755 & 1.040675 & 20.22530 & 10.52938 & 6.745710 & 15.21135 & 0.893461 & 21.51324 & 4.288010 \\
\hline 8 & 8.166694 & 11.12823 & 1.144032 & 20.51788 & 10.47610 & 6.928461 & 15.26397 & 0.874312 & 21.22080 & 4.279517 \\
\hline 9 & 8.052513 & 11.09430 & 1.225272 & 20.66989 & 10.42284 & 7.076330 & 15.28967 & 0.861576 & 21.04076 & 4.266853 \\
\hline 10 & 7.986398 & 11.08739 & 1.287295 & 20.73900 & 10.37423 & 7.197356 & 15.29837 & 0.853071 & 20.92427 & 4.252614 \\
\hline
\end{tabular}

cause CCMP, NKY, FTSE Top 40 and MXZA stock indices, respectively. Moreover, such specifications in the dynamics among the two stock indices and across the respective stock indices reiterates that the degree in stock market linkages varies through time.

However, the bidirectional causality indicates direction of causality, but is unable to determine the magnitude of causation. Hence, VDA has been introduced to measure the degrees of causation and linkages through the various lag information sets of global stock indices. SPX stock index has been influenced approximately by 3 percent through the lagged information of NKY stock index, which, in turn, reflects that meagre information set of global stock indices can be used to measure the variations in returns. However, the stock indices namely CCMP Index, SX5E Index, UKX Index, NKY Index, HSI Index, CNX 500 index, TA-100 Index, FTSE Top 40 Index and MXZA index can influence the variations in returns of the respective stock indices through the cross-sectional information of lagged information set of global stock indices. Thus, at this juncture, the SPX stock index emerges as the lead index to discover the stock price and simultaneously transmit the information set reflecting in the rest of the global stock indices. The evidences reveal a strong indication of linkages among the global stock indices reflecting the persistence of dynamic dimensional proponents.

The time-varying global market inefficiency has been examined to diagnose the degree of linkages and its dynamic persistence, and hence, the timevarying regression along with the volatility factors revealed that the coefficient of determination varies in the two sets of the respective data sample periods namely, the full sample period and the subprime crisis period. The time-varying beta coefficients between the two sets of sample period in the respective regression specification infer simultaneous fluctuations over the period of time, and hence, the significant difference has been observed in the beta coefficients for the respective state variables in the respective regression. The regression specification further entails the evidences supporting time-varying financial global market inefficiency.

\section{Conclusion}

The time-varying global market inefficiency, explicitly the world stock market linkages, is the central theme of the present study and consequently has been examined over the short-horizon as well as longer-horizon periods. The variations in stock returns among global stock indices can be observed across the different time periods namely, full sample period, presubprime crisis period, subprime crisis period and post-subprime crisis period, respectively. The shorthorizon dynamics is the foremost in importance among influential proponents to examine since the investors eye to invest in stock on the short-term basis and, in turn, seek to maximize the returns and minimize the risk through holding the diversified portfolio. Hence, the short-horizon dynamics among the global stock indices evidenced in the study unlock various dimensions persisting in both the Indian stock market and the global stock market.

Moreover, the inferences with evidences entail the persistence of time-varying global stock market inefficiency. The variations in the degrees of relative stock market inefficiency and the persistence of global market linkages provide the rational investors and arbitrageurs successively holding the basket of inter-national diversified stock portfolio, with an opportunity set to create an arbitrage position through maximization of the overall returns. The process of exploiting the available opportunity set by the rational investors resulting from the global stock market linkages and time-varying global stock market inefficiency has been evidenced in the full sample 
Table 9 Time-varying Beta employing GARCH $(1,1)$ in OLS

\begin{tabular}{|c|c|c|c|c|c|}
\hline \multicolumn{6}{|c|}{ Full sample period (January 1996 to December 2013) } \\
\hline Global indices & $\alpha$ & $\beta$ & $\operatorname{SE}(\beta)$ & (z) Statistics & $\overline{\boldsymbol{R}}^{2}$ \\
\hline \multicolumn{6}{|c|}{ 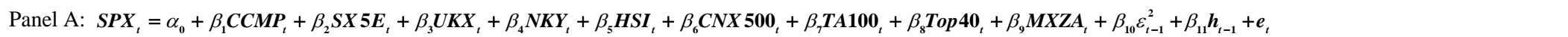 } \\
\hline CCMP & $0.783 * * *$ & $0.476 * * *$ & 0.020 & 23.770 & 0.875 \\
\hline SX5E & $0.783 * * *$ & -0.033 & 0.022 & -1.517 & 0.875 \\
\hline UKX & $0.783 * * *$ & $0.518 * * *$ & 0.032 & 16.179 & 0.875 \\
\hline NKY & $0.783 * * *$ & $-0.034 *$ & 0.019 & -1.744 & 0.875 \\
\hline HSI & $0.783 * * *$ & $-0.0329 * *$ & 0.014 & -2.239 & 0.875 \\
\hline CNX 500 & $0.783 * * *$ & $-0.040^{* * *}$ & 0.009 & -4.124 & 0.875 \\
\hline TA-100 & $0.783 * * *$ & $-0.074 * * *$ & 0.011 & 06.538 & 0.875 \\
\hline FTSE Top 40 & $0.783 * * *$ & $-0.104 * *$ & 0.051 & -2.022 & 0.875 \\
\hline MXZA & $0.783 * * *$ & 0.069 & 0.048 & 1.439 & 0.875 \\
\hline$\varepsilon_{t-1}^{2}$ & $1.003 * *$ & $0.966 * * *$ & 0.195 & 4.941 & 0.875 \\
\hline$h_{t-1}$ & $1.003 * *$ & 0.144 & 0.100 & 1.433 & 0.875 \\
\hline \multicolumn{6}{|c|}{ Panel B: $\boldsymbol{C C M P} \boldsymbol{P}_{t}=\alpha_{0}+\beta_{1} \boldsymbol{S P X} \boldsymbol{X}_{t}+\beta_{2} \boldsymbol{S X} \mathbf{5} \boldsymbol{E}_{t}+\beta_{3} \boldsymbol{U} \boldsymbol{K} \boldsymbol{X}_{t}+\beta_{4} N K Y_{t}+\beta_{5} \mathrm{HSI}_{t}+\beta_{6} \boldsymbol{C N X} \mathbf{5 0 0}+\beta_{7} \boldsymbol{T A 1 0 0}_{t}+\beta_{8} \mathrm{FTSETop40}_{t}+\beta_{9} \boldsymbol{M X Z A}_{t}+\beta_{10} \varepsilon_{t-1}^{2}+\beta_{11} \boldsymbol{h}_{t-1}+\boldsymbol{e}_{t}$} \\
\hline SPX & 0.289 & $10193 * * *$ & 0.049 & 23.990 & 0.843 \\
\hline SX5E & 0.289 & $0.116^{* * *}$ & 0.036 & 3.214 & 0.843 \\
\hline UKX & 0.289 & $-0.400 * * *$ & 0.058 & -6.860 & 0.843 \\
\hline NKY & 0.289 & $0.063 * *$ & 0.027 & 2.292 & 0.843 \\
\hline HSI & 0.289 & $0.161 * * *$ & 0.029 & 5.394 & 0.843 \\
\hline CNX 500 & 0.289 & $0.063 * * *$ & 0.018 & 3.335 & 0.843 \\
\hline TA-100 & 0.289 & $0.188 * * *$ & 0.013 & 14.218 & 0.843 \\
\hline FTSE Top 40 & 0.289 & $-0.663^{* * *}$ & 0.081 & -8.179 & 0.843 \\
\hline MXZA & 0.289 & $0.582 * * *$ & 0.081 & 7.178 & 0.843 \\
\hline$\varepsilon_{t-1}^{2}$ & $2.239 * *$ & $1.078 * * *$ & 0.222 & 4.852 & 0.843 \\
\hline$h_{t-1}$ & $2.239 * *$ & $0.121 * * *$ & 0.045 & 2.661 & 0.843 \\
\hline \multicolumn{6}{|c|}{ 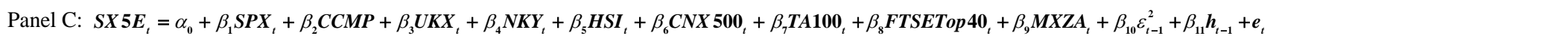 } \\
\hline SPX & -0.117 & $0.123^{*}$ & 0.073 & 1.676 & 0.754 \\
\hline CCMP & -0.117 & -0.047 & 0.043 & -1.091 & 0.754 \\
\hline UKX & -0.117 & $0.807 * * *$ & 0.056 & 14.392 & 0.754 \\
\hline NKY & -0.117 & 0.008 & 0.029 & 0.278 & 0.754 \\
\hline
\end{tabular}


Table 9 continued

\begin{tabular}{|c|c|c|c|c|c|}
\hline \multicolumn{6}{|c|}{ Full sample period (January 1996 to December 2013) } \\
\hline Global indices & $\alpha$ & $\beta$ & $\operatorname{SE}(\beta)$ & (z) Statistics & $\overline{\boldsymbol{R}}^{2}$ \\
\hline HSI & -0.117 & $0.169 * * *$ & 0.034 & 4.864 & 0.754 \\
\hline CNX 500 & -0.117 & $0.045^{* *}$ & 0.022 & 1.983 & 0.754 \\
\hline TA-100 & -0.117 & $0.127 * * *$ & 0.026 & 4.863 & 0.754 \\
\hline FTSE Top 40 & -0.117 & $-0.396 * * *$ & 0.085 & -4.622 & 0.754 \\
\hline MXZA & -0.117 & $0.271 * * *$ & 0.090 & 3.003 & 0.754 \\
\hline$\varepsilon_{t-1}^{2}$ & $2.678 * *$ & $1.219 * * *$ & 0.189 & 3.688 & 0.754 \\
\hline$h_{t-1}$ & $2.678 * *$ & $0.275^{* *}$ & 0.118 & 2.334 & 0.754 \\
\hline \multicolumn{6}{|c|}{ 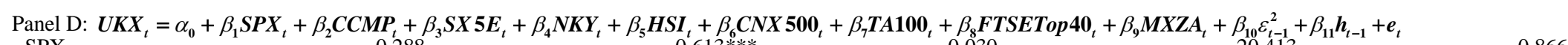 } \\
\hline CCMP & -0.288 & $-0.298 * * *$ & 0.026 & -11.097 & 0.866 \\
\hline SX5E & -0.288 & $0.394 * * *$ & 0.017 & 23.220 & 0.866 \\
\hline NKY & -0.288 & -0.024 & 0.017 & -1.365 & 0.866 \\
\hline HSI & -0.288 & $0.138 * * *$ & 0.016 & 8.199 & 0.866 \\
\hline CNX 500 & -0.288 & -0.017 & 0.013 & -1.340 & 0.866 \\
\hline TA-100 & -0.288 & $0.053 * * *$ & 1.014 & 3.804 & 0.866 \\
\hline FTSE Top 40 & -0.288 & $0.095^{*}$ & 0.056 & 1.695 & 0.866 \\
\hline MXZA & -0.288 & 0.006 & 0.051 & 0.129 & 0.866 \\
\hline$\varepsilon_{t-1}^{2}$ & $1.869 * * *$ & $1.044 * * *$ & 0.235 & 4.426 & 0.866 \\
\hline$h_{t-1}$ & $1.869^{* * *}$ & 0.013 & 0.031 & 0.426 & 0.866 \\
\hline \multicolumn{6}{|c|}{ 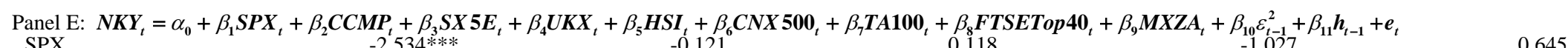 } \\
\hline CCMP & $-2.534 * * *$ & $0.547 * * *$ & 0.066 & 8.279 & 0.645 \\
\hline SX5E & $-2.534 * * *$ & 0.013 & 0.065 & 0.200 & 0.645 \\
\hline UKX & $-2.534 * * *$ & $-0.170 * *$ & 0.088 & -1.929 & 0.645 \\
\hline HSI & $-2.534 * * *$ & 0.012 & 0.054 & 0.225 & 0.645 \\
\hline CNX 500 & $-2.534 * * *$ & -0.022 & 0.035 & -0.622 & 0.645 \\
\hline TA-100 & $-2.534 * * *$ & $-0.195^{* * *}$ & 0.024 & -7.937 & 0.645 \\
\hline FTSE Top 40 & $-2.534 * * *$ & $1.020 * * *$ & 0.160 & 6.363 & 0.645 \\
\hline MXZA & $-2.534 * * *$ & $-0.667 * * *$ & 0.158 & -4.219 & 0.645 \\
\hline$\varepsilon_{t-1}^{2}$ & $4.132 *$ & $0.634 * * *$ & 0.173 & 3.655 & 0.645 \\
\hline $\boldsymbol{h}_{t-1}$ & $4.132 *$ & $0.403 * * *$ & 0.095 & 4.204 & 0.645 \\
\hline
\end{tabular}


Table 9 continued

\begin{tabular}{|c|c|c|c|c|c|}
\hline \multicolumn{6}{|c|}{ Full sample period (January 1996 to December 2013) } \\
\hline Global indices & $\alpha$ & $\beta$ & $\operatorname{SE}(\beta)$ & (z) Statistics & $\overline{\boldsymbol{R}}^{2}$ \\
\hline \multicolumn{6}{|c|}{ 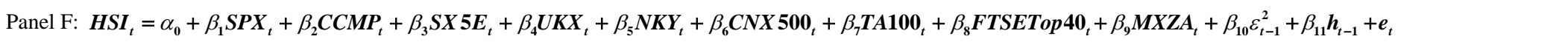 } \\
\hline SPX & $-1.400 * * *$ & $-0.526 * * *$ & 0.082 & -6.407 & 0.756 \\
\hline CCMP & $-1.400 * * *$ & $0.410 * * *$ & 0.049 & 8.223 & 0.756 \\
\hline SX5E & $-1.400 * * *$ & $-0.100 *$ & 0.052 & -1.931 & 0.756 \\
\hline UKX & $-1.400 * * *$ & $0.553 * * *$ & 0.081 & 6.775 & 0.756 \\
\hline NKY & $-1.400 * * *$ & 0.052 & 0.038 & 1.343 & 0.756 \\
\hline CNX 500 & $-1.400 * * *$ & $0.263 * * *$ & 0.025 & 10.503 & 0.756 \\
\hline TA-100 & $-1.400 * * *$ & 0.007 & 0.029 & 0.244 & 0.756 \\
\hline FTSE Top 40 & $-1.400 * * *$ & $0.862 * * *$ & 0.096 & 8.958 & 0.756 \\
\hline MXZA & -1.400 & $-0.752 * * *$ & 0.090 & -8.301 & 0.756 \\
\hline$\varepsilon_{t-1}^{2}$ & $10.049 * * *$ & $1.228 * * *$ & 0.271 & 4.520 & 0.756 \\
\hline$h_{t-1}$ & $10.049 * * *$ & -0.010 & -0.706 & -0.706 & 0.756 \\
\hline \multicolumn{6}{|c|}{ 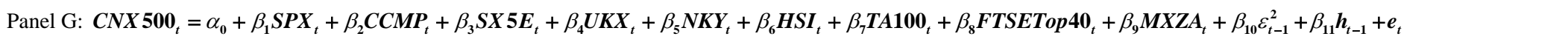 } \\
\hline SPX & $3.869 * * *$ & $-1.396^{* * *}$ & 0.160 & -8.711 & 0.792 \\
\hline CCMP & $3.869 * * *$ & $0.464 * * *$ & 0.100 & 4.602 & 0.792 \\
\hline SX5E & $3.869 * * *$ & $0.306 * * *$ & 0.115 & 2.648 & 0.792 \\
\hline UKX & $3.869 * * *$ & 0.209 & 0.175 & 1.198 & 0.792 \\
\hline NKY & $3.869 * * *$ & -0.009 & 0.092 & -0.103 & 0.792 \\
\hline HSI & $3.869 * * *$ & $0.419 * * *$ & 0.076 & 5.494 & 0.792 \\
\hline TA-100 & $3.869 * * *$ & $0.362 * * *$ & 0.059 & 6.112 & 0.792 \\
\hline FTSE Top 40 & $3.869 * * *$ & -0.188 & 0.267 & -0.704 & 0.792 \\
\hline MXZA & $3.869 * * *$ & $0.747 * * *$ & 0.248 & 3.008 & 0.792 \\
\hline$\varepsilon_{t-1}^{2}$ & $30.639 * *$ & $0.483 * * *$ & 0.167 & 2.888 & 0.792 \\
\hline$h_{t-1}$ & $30.639 * *$ & $0.306^{* *}$ & 0.137 & 2.237 & 0.792 \\
\hline \multicolumn{6}{|c|}{ 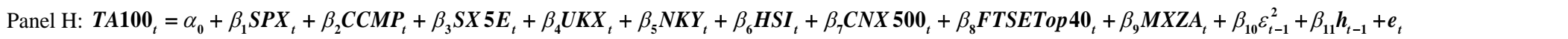 } \\
\hline SPX & $2.733 * * *$ & $0.675^{* * *}$ & 0.095 & 7.096 & 0.645 \\
\hline CCMP & $2.733 * * *$ & 0.051 & 0.054 & 0.943 & 0.645 \\
\hline SX5E & $2.733 * * *$ & $0.178 * * *$ & 0.058 & 3.051 & 0.645 \\
\hline UKX & $2.733 * * *$ & $-0.340 * * *$ & 0.104 & -3.263 & 0.645 \\
\hline NKY & $2.733 * * *$ & 0.005 & 0.042 & 0.118 & 0.645 \\
\hline
\end{tabular}


Table 9 continued

\begin{tabular}{|c|c|c|c|c|c|}
\hline \multicolumn{6}{|c|}{ Full sample period (January 1996 to December 2013) } \\
\hline Global indices & $\alpha$ & $\beta$ & $\operatorname{SE}(\beta)$ & (z) Statistics & $\overline{\boldsymbol{R}}^{2}$ \\
\hline HSI & $2.733 * * *$ & $0.094 * *$ & 0.045 & 2.097 & 0.645 \\
\hline CNX 500 & $2.733 * * *$ & $0.366^{* * *}$ & 0.028 & 12.931 & 0.645 \\
\hline FTSE Top 40 & $2.733 * * *$ & $-0.237 * *$ & 0.119 & -1.987 & 0.645 \\
\hline MXZA & $2.733 * * *$ & $0.346 * * *$ & 0.112 & 3.068 & 0.645 \\
\hline$\varepsilon_{t-1}^{2}$ & $8.482 * * *$ & $1.310 * * *$ & 0.256 & 5.101 & 0.645 \\
\hline$h_{t-1}$ & $8.482 * * *$ & -0.012 & 0.044 & -0.284 & 0.645 \\
\hline \multicolumn{6}{|c|}{ 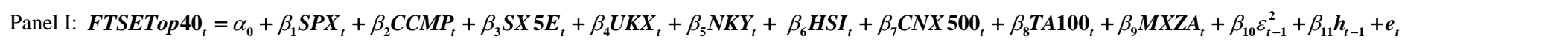 } \\
\hline SPX & $1.504 * * *$ & $-0.107 * * *$ & 0.030 & -3.519 & 0.964 \\
\hline CCMP & $1.504 * * *$ & $-0.127 * * *$ & 0.019 & -6.379 & 0.964 \\
\hline SX5E & $1.504 * * *$ & $0.042 * *$ & 0.019 & 2.182 & 0.964 \\
\hline UKX & $1.504 * * *$ & 0.271 & 0.032 & 8.275 & 0.964 \\
\hline NKY & $1.504 * * *$ & $0.110 * * *$ & 0.014 & 7.827 & 0.964 \\
\hline HSI & $1.504 * * *$ & $0.077 * * *$ & 0.013 & 5.925 & 0.964 \\
\hline CNX 500 & $1.504 * * *$ & $-0.026 * * *$ & 0.008 & -2.991 & 0.964 \\
\hline TA-100 & $1.504 * * *$ & $0.026 * * *$ & 0.008 & 3.176 & 0.964 \\
\hline MXZA & $1.504 * * *$ & $0.898 * * *$ & 0.010 & 85.061 & 0.964 \\
\hline$\varepsilon_{t-1}^{2}$ & $0.556^{*}$ & $0.946 * * *$ & 0.236 & 4.000 & 0.964 \\
\hline$h_{t-1}$ & $0.556^{*}$ & 0.194 & 0.083 & 2.317 & 0.964 \\
\hline \multicolumn{6}{|c|}{ 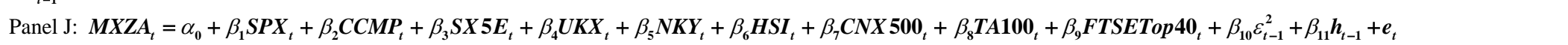 } \\
\hline SPX & $0.910^{* * *}$ & 0.045 & 0.031 & 1.429 & 0.951 \\
\hline CCMP & $0.910^{* * *}$ & $0.110 * * *$ & 0.022 & 4.943 & 0.951 \\
\hline SX5E & $0.910 * * *$ & $-0.120 * * *$ & 0.018 & -6.426 & 0.951 \\
\hline UKX & $0.910 * * *$ & $-0.109 * * *$ & 0.028 & -3.886 & 0.951 \\
\hline NKY & $0.910 * * *$ & $-0.111 * * *$ & 0.020 & -5.356 & 0.951 \\
\hline HSI & $0.910 * * *$ & $-0.073 * * *$ & 0.012 & -5.706 & 0.951 \\
\hline CNX 500 & $0.910 * * *$ & $0.042 * * *$ & 0.007 & 5.394 & 0.951 \\
\hline TA-100 & $0.910 * * *$ & 0.004 & 0.008 & 0.501 & 0.951 \\
\hline FTSE Top 40 & $0.910 * * *$ & $1.030 * * *$ & 0.013 & 75.908 & 0.951 \\
\hline$\varepsilon_{t-1}^{2}$ & $0.542 * * *$ & $0.935^{* * *}$ & 0.234 & 3.990 & 0.951 \\
\hline$h_{t-1}$ & $0.542 * * *$ & $0.221 * *$ & 0.105 & 2.094 & 0.951 \\
\hline
\end{tabular}

$*, * *$, and $* * *$ indicates significance at 10,5 and $1 \%$ level, respectively 
Table 10 Time-varying beta estimation employing GARCH $(1,1)$ in OLS

\begin{tabular}{|c|c|c|c|c|c|}
\hline \multicolumn{6}{|c|}{ Subprime crisis period (July 2007 to December 2008) } \\
\hline Global indices & $\alpha$ & $\beta$ & $\operatorname{SE}(\beta)$ & (z) Statistics & $\overline{\boldsymbol{R}}^{2}$ \\
\hline \multicolumn{6}{|c|}{ 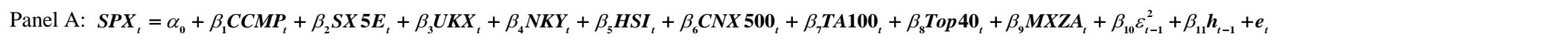 } \\
\hline CCMP & 0.126 & $0.638 * *$ & 0.225 & 2.835 & 0.773 \\
\hline SX5E & 0.126 & 0.580 & 0.413 & 1.404 & 0.773 \\
\hline UKX & 0.126 & $0.461 *$ & 0.248 & 1.859 & 0.773 \\
\hline NKY & 0.126 & 0.183 & 0.114 & 1.607 & 0.773 \\
\hline HSI & 0.126 & -0.357 & 0.250 & -1.426 & 0.773 \\
\hline CNX 500 & 0.126 & 0.133 & 0.139 & 0.960 & 0.773 \\
\hline TA-100 & 0.126 & $-0.394 * * *$ & 0.123 & -3.186 & 0.773 \\
\hline FTSE Top 40 & 0.126 & -0.066 & 0.263 & -0.253 & 0.773 \\
\hline MXZA & 0.126 & 0.091 & 0.365 & 0.251 & 0.773 \\
\hline$\varepsilon_{t-1}^{2}$ & -0.033 & 0.146 & 1.067 & 0.137 & 0.773 \\
\hline$h_{t-1}$ & -0.033 & $1.482 * *$ & 0.688 & 2.153 & 0.773 \\
\hline \multicolumn{6}{|c|}{ 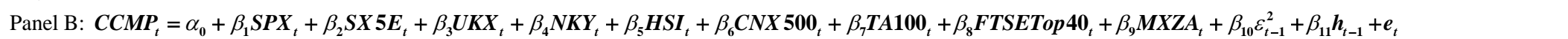 } \\
\hline SPX & -0.266 & $1.267 * *$ & 0.598 & 2.115 & 0.659 \\
\hline SX5E & -0.266 & -0.539 & 0.572 & -0.941 & 0.659 \\
\hline UKX & -0.266 & -0.330 & 0.633 & -0.521 & 0.659 \\
\hline NKY & -0.266 & $-0.481 * *$ & 0.225 & -2.135 & 0.659 \\
\hline HSI & -0.266 & 0.188 & 0.282 & 0.667 & 0.659 \\
\hline CNX 500 & -0.266 & -0.152 & 0.098 & -1.543 & 0.659 \\
\hline TA-100 & -0.266 & 0.528 & 0.357 & 1.480 & 0.659 \\
\hline FTSE Top 40 & -0.266 & 0.091 & 1.007 & 0.090 & 0.659 \\
\hline MXZA & -0.266 & 0.114 & 0.547 & 0.209 & 0.659 \\
\hline$\varepsilon_{t-1}^{2}$ & 0.481 & -0.257 & 0.375 & -0.685 & 0.659 \\
\hline$h_{t-1}$ & 0.481 & 1.027 & 2.616 & 0.392 & 0.659 \\
\hline \multicolumn{6}{|c|}{ 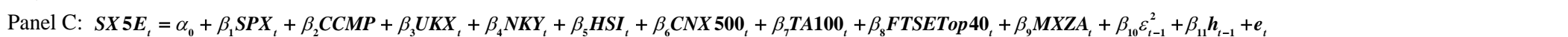 } \\
\hline SPX & -0.509 & $1.240 * * *$ & 0.172 & 7.191 & 0.759 \\
\hline СCMP & -0.509 & $-0.643 * *$ & 0.308 & -2.085 & 0.759 \\
\hline UKX & -0.509 & $-0.795 * * *$ & 0.174 & -4.550 & 0.759 \\
\hline NKY & -0.509 & -0.300 & 0.229 & -1.312 & 0.759 \\
\hline HSI & -0.509 & $0.312 * * *$ & 0.113 & 2.751 & 0.759 \\
\hline CNX 500 & -0.509 & $-0.118 * *$ & 0.062 & -1.883 & 0.759 \\
\hline
\end{tabular}


Table 10 continued

\begin{tabular}{|c|c|c|c|c|c|}
\hline \multicolumn{6}{|c|}{ Subprime crisis period (July 2007 to December 2008) } \\
\hline Global indices & $\alpha$ & $\beta$ & $\operatorname{SE}(\beta)$ & (z) Statistics & $\overline{\boldsymbol{R}}^{2}$ \\
\hline TA-100 & -0.509 & $0.424 * * *$ & 0.137 & 3.086 & 0.759 \\
\hline FTSE Top 40 & -0.509 & $0.281 *$ & 0.168 & 1.675 & 0.759 \\
\hline MXZA & -0.509 & 0.001 & 0.369 & 0.002 & 0.759 \\
\hline$\varepsilon_{t-1}^{2}$ & 0.661 & 1.625 & 3.369 & 0.482 & 0.759 \\
\hline$h_{t-1}$ & 0.661 & -0.287 & 1.042 & -0.275 & 0.759 \\
\hline \multicolumn{6}{|c|}{ 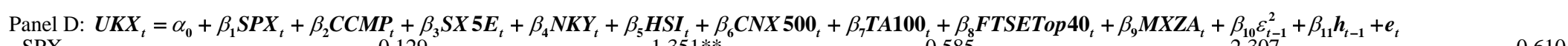 } \\
\hline CCMP & -0.129 & -0.624 & 0.436 & -1.429 & 0.610 \\
\hline SX5E & -0.129 & $-0.852^{* *}$ & 0.428 & -1.991 & 0.610 \\
\hline NKY & -0.129 & -0.270 & 0.308 & -0.877 & 0.610 \\
\hline HSI & -0.129 & $0.393 * *$ & 0.163 & 2.411 & 0.610 \\
\hline CNX 500 & -0.129 & -0.132 & 0.110 & -1.200 & 0.610 \\
\hline TA-100 & -0.129 & 0.335 & 0.310 & 1.081 & 0.610 \\
\hline FTSE Top 40 & -0.129 & 0.285 & 0.528 & 0.539 & 0.610 \\
\hline MXZA & -0.129 & -0.029 & 0.638 & -0.046 & 0.610 \\
\hline$\varepsilon_{t-1}^{2}$ & 0.289 & -0.271 & 0.331 & -0.819 & 0.610 \\
\hline$h_{t-1}$ & 0.289 & 1.149 & 0.897 & 1.280 & 0.610 \\
\hline \multicolumn{6}{|c|}{ 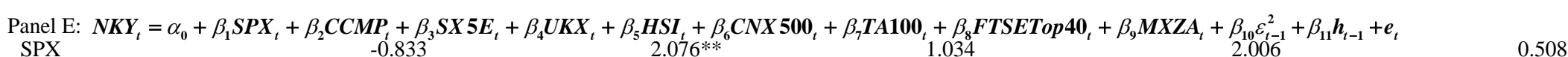 } \\
\hline СCMP & -0.833 & $-1.278 * *$ & 0.566 & -2.258 & 0.508 \\
\hline SX5E & -0.833 & -0.877 & 0.942 & -0.931 & 0.508 \\
\hline UKX & -0.833 & -0.398 & 0.549 & -0.725 & 0.508 \\
\hline HSI & -0.833 & 0.278 & 0.633 & 0.440 & 0.508 \\
\hline CNX 500 & -0.833 & -0.218 & 0.311 & -0.699 & 0.508 \\
\hline TA-100 & -0.833 & 0.815 & 0.716 & 1.139 & 0.508 \\
\hline FTSE Top40 & -0.833 & 0.102 & 0.274 & 0.374 & 0.508 \\
\hline MXZA & -0.833 & 0.022 & 0.962 & 0.023 & 0.508 \\
\hline$\varepsilon_{t-1}^{2}$ & 0.022 & 1.883 & 3.337 & 0.564 & 0.508 \\
\hline$h_{t-1}$ & 0.022 & -0.140 & 1.701 & -0.082 & 0.508 \\
\hline
\end{tabular}


Table 10 continued

\begin{tabular}{|c|c|c|c|c|c|}
\hline \multicolumn{6}{|c|}{ Subprime crisis period (July 2007 to December 2008) } \\
\hline Global indices & $\alpha$ & $\beta$ & $\mathrm{SE}(\beta)$ & (z) Statistics & $\overline{\boldsymbol{R}}^{2}$ \\
\hline \multicolumn{6}{|c|}{ 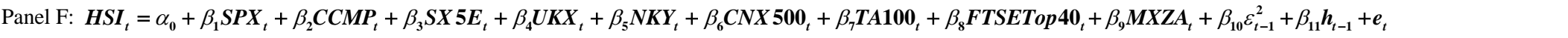 } \\
\hline SPX & 0.443 & $-2.330 * * *$ & 0.850 & -2.739 & 0.703 \\
\hline CCMP & 0.443 & $1.609 *$ & 0.897 & 1.794 & 0.703 \\
\hline SX5E & 0.443 & $1.310^{* *}$ & 0.617 & 2.123 & 0.703 \\
\hline UKX & 0.443 & $1.028 * * *$ & 0.277 & 3.701 & 0.703 \\
\hline NKY & 0.443 & 0.414 & 0.557 & 0.743 & 0.703 \\
\hline CNX 500 & 0.443 & $0.394 * *$ & 0.179 & 2.200 & 0.703 \\
\hline TA-100 & 0.443 & $-1.073 * * *$ & 0.400 & -2.682 & 0.703 \\
\hline FTSE Top 40 & 0.443 & 0.063 & 0.412 & 0.153 & 0.703 \\
\hline MXZA & 0.443 & 0.235 & 0.465 & 0.506 & 0.703 \\
\hline$\varepsilon_{t-1}^{2}$ & -0.411 & 0.472 & 1.793 & 0.263 & 0.703 \\
\hline$h_{t-1}$ & -0.411 & 1.640 & 1.660 & 0.988 & 0.703 \\
\hline \multicolumn{6}{|c|}{ Panel G: $\boldsymbol{C N X ~ 5 0 0}=\alpha_{0}+\beta_{1} S P X_{t}+\beta_{2} \boldsymbol{C C M P}+\beta_{3} S X 5 E_{t}+\beta_{4} U K X_{t}+\beta_{5} N K Y_{t}+\beta_{6} H_{S I}+\beta_{7}$ TA100 $_{t}+\beta_{8}$ FTSETop40 $_{t}+\beta_{9}$ MXZA $_{t}+\beta_{10} \varepsilon_{t-1}^{2}+\beta_{11} \boldsymbol{h}_{t-1}+e_{t}$} \\
\hline SPX & 0.018 & $3.780 *$ & 2.078 & 1.818 & 0.764 \\
\hline CCMP & 0.018 & $-2.197 *$ & 1.168 & -1.881 & 0.764 \\
\hline SX5E & 0.018 & -0.997 & 1.574 & -0.633 & 0.764 \\
\hline UKX & 0.018 & -1.300 & 1.442 & -0.901 & 0.764 \\
\hline NKY & 0.018 & -1.222 & 0.808 & -1.512 & 0.764 \\
\hline HSI & 0.018 & $1.820 *$ & 0.948 & 1.918 & 0.764 \\
\hline TA-100 & 0.018 & $1.616 * * *$ & 0.596 & 2.709 & 0.764 \\
\hline FTSE Top 40 & 0.018 & -0.262 & 0.926 & -0.283 & 0.764 \\
\hline MXZA & 0.018 & -0.616 & 1.588 & -0.388 & 0.764 \\
\hline$\varepsilon_{t-1}^{2}$ & 7.613 & -0.258 & 0.636 & -0.406 & 0.764 \\
\hline$h_{t-1}$ & 7.613 & 0.911 & 1.318 & 0.691 & 0.764 \\
\hline \multicolumn{6}{|c|}{ Panel H: TA100 $_{t}=\alpha_{0}+\beta_{1} S P X_{t}+\beta_{2} C C M P_{t}+\beta_{3} S X 5 E_{t}+\beta_{4} U K X_{t}+\beta_{5} N K Y_{t}+\beta_{6} H_{S I}+\beta_{7} C N X 5_{500}+\beta_{8} F_{T S E T o p 40}+\beta_{9} M_{X Z A_{t}}+\beta_{10} \varepsilon_{t-1}^{2}+\beta_{11} h_{t-1}+e_{t}$} \\
\hline SPX & 0.494 & $-1.743 * *$ & 0.761 & -2.290 & 0.734 \\
\hline CCMP & 0.494 & $1.339 * * *$ & 0.397 & 3.372 & 0.734 \\
\hline SX5E & 0.494 & $0.919 *$ & 0.500 & 1.836 & 0.734 \\
\hline UKX & 0.494 & 0.637 & 0.569 & 1.119 & 0.734 \\
\hline NKY & 0.494 & 0.343 & 0.276 & 1.244 & 0.734 \\
\hline HSI & 0.494 & $-0.765 * * *$ & 0.299 & -2.555 & 0.734 \\
\hline
\end{tabular}


Table 10 continued

\begin{tabular}{|c|c|c|c|c|c|}
\hline \multicolumn{6}{|c|}{ Subprime crisis period (July 2007 to December 2008) } \\
\hline Global indices & $\alpha$ & $\beta$ & S.E. (b) & (z) Statistics & $\overline{\boldsymbol{R}}^{2}$ \\
\hline CNX 500 & 0.494 & $0.347 * * *$ & 0.120 & 2.878 & 0.734 \\
\hline FTSE Top 40 & 0.494 & 0.269 & 0.312 & 0.862 & 0.734 \\
\hline MXZA & 0.494 & 0.083 & 0.417 & 0.201 & 0.734 \\
\hline$\varepsilon_{t-1}^{2}$ & -0.269 & 0.477 & 1.755 & 0.272 & 0.734 \\
\hline$h_{t-1}$ & -0.269 & 1.599 & 1.958 & 0.816 & 0.734 \\
\hline \multicolumn{6}{|c|}{ 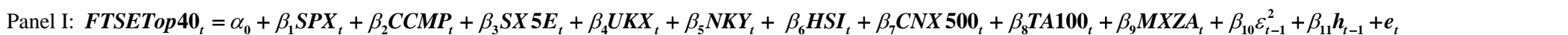 } \\
\hline SPX & 0.116 & -0.726 & 2.512 & -0.289 & 0.772 \\
\hline CCMP & 0.116 & 0.049 & 1.520 & 0.032 & 0.772 \\
\hline SX5E & 0.116 & 0.581 & 0.827 & 0.702 & 0.772 \\
\hline UKX & 0.116 & 0.671 & 0.969 & 0.693 & 0.772 \\
\hline NKY & 0.116 & 0.091 & 1.552 & 0.059 & 0.772 \\
\hline HSI & 0.116 & -0.054 & 0.863 & -0.062 & 0.772 \\
\hline CNX 500 & 0.116 & -0.047 & 0.621 & -0.075 & 0.772 \\
\hline TA-100 & 0.116 & 0.131 & 1.007 & 0.130 & 0.772 \\
\hline MXZA & 0.116 & 0.560 & 0.658 & 0.851 & 0.772 \\
\hline$\varepsilon_{t-1}^{2}$ & 1.196 & -0.121 & 0.100 & -1.208 & 0.772 \\
\hline$h_{t-1}$ & 1.196 & 0.817 & 0.703 & 1.161 & 0.772 \\
\hline \multicolumn{6}{|c|}{ 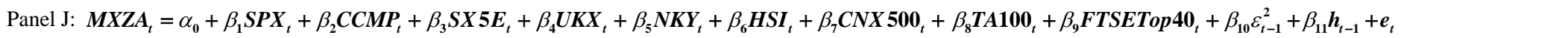 } \\
\hline SPX & 0.426 & 0.210 & 0.722 & 0.292 & 0.757 \\
\hline CCMP & 0.426 & 0.150 & 0.520 & 0.289 & 0.757 \\
\hline SX5E & 0.426 & 0.139 & 0.509 & 0.274 & 0.757 \\
\hline UKX & 0.426 & -0.137 & 0.505 & -0.272 & 0.757 \\
\hline NKY & 0.426 & 0.060 & 0.336 & 0.180 & 0.757 \\
\hline HSI & 0.426 & 0.292 & 0.228 & 1.281 & 0.757 \\
\hline CNX 500 & 0.426 & -0.091 & 0.143 & -0.640 & 0.757 \\
\hline TA-100 & 0.426 & -0.053 & 0.290 & -0.185 & 0.757 \\
\hline FTSE Top 40 & 0.426 & $0.551 * *$ & 0.241 & 2.281 & 0.757 \\
\hline$\varepsilon_{t-1}^{2}$ & 1.504 & -0.292 & 0.435 & -0.672 & 0.757 \\
\hline $\boldsymbol{h}_{t-1}$ & 1.504 & 0.838 & 1.209 & 0.693 & 0.757 \\
\hline
\end{tabular}


study period. The evidence successively revealed the presence of high degree of relative time-varying global stock market inefficiency during the study period and, in turn, revealed the persistence of informational asymmetry which could result in forming the arbitrage setup and simultaneously incur the excess returns. However, the information set of global market linkages certainly dies through the passage of time when the information set fully reflects in the global stock price, forming the state of price equilibrium. Hence, simultaneously the degree of global stock market inefficiency relatively varies over and across the period of time and leads to global stock market forming the state of joint efficiency. The time-varying beta coefficients further enhance to entangle the puzzle that persists over the period of subprime crisis through revealing the respective stock market forming global stock index which is relatively more efficient in nature.

\section{References}

Akbas F, Armstrong WJ, Sorescu S, Subrahmanyam A (2014) AFA 2013 San Diego Meetings Paper. Available at http://ssrn.com/abstract=2022485

Alexander SS (1961) Price movements in speculative markets: trends or random walks. Ind Manag Rev $2: 7-26$

Bariviera AF, Guercio MB, Martinez LB (2012) A comparative analysis of the informational efficiency of the fixed income market in seven European countries. Econ Lett 116:426-428

Bollerslev T (1986) Generalized autoregressive conditional heteroskedasticity. J Econ 31:307327

Campbell JY, Lo AW, MacKinlay AC (1997) The econometrics of financial markets. Princeton University Press, New Jersey

Choudhry T, Jayasekera R (2013) Level of efficiency in the UK equity market: empirical study of the effects of the global financial crisis. Rev Quant Financ Account 1-30. doi:10. 1007/s11156-0130404-6

Chuluun T, Eun CS, Kilic, R (2011) Investment intensity of currencies and the random walk hypothesis: cross-currency evidence. J Bank Financ 35(2):372-387

Colisk J (1996) Why bounded rationality? J Econ Lit 34(2):669-700
Cootner P (1962) Stock prices: random vs. systematic changes. Ind Manag Rev 3:24-45

Cristina C, Maria CD, Mircea BH (2012) Global financial crisis and unit-linked insurance markets efficiency: empirical evidence from central and eastern European Countries. Ann Fac Econ 1(2):443-448

Cutler DM, Poterba JM Summers LH (1990) Speculative dynamics and the role of feedback traders. Working papers 545, Massachusetts Institute of Technology (MIT), Department of Economics

Doran JS, Peterson DR, Wright C (2010) Confidence, opinions of market efficiency, and investment behavior of finance professors. J Financ Mark 13:174-195

Dungey M, Fry R, Hermosillo BG, Martin VL, and Tang C (2008) Are financial crises alike? Working paper no. 15, Centre for Applied Macroeconomic Analysis, Canberra, pp 1-58

Dunis CL, Morrison V (2007) The economic value of advanced time-series methods for modelling and trading 10-year government bonds. Eur J Financ 13(4):333-352

Enders W (2004) Applied econometric time-series. Wiley, Singapore

Engle RF, Kroner KF (1995) Multivariate simultaneous gen-eralized ARCH. Econ Theory 11(1):122-150

Eun CS, Shim S (1989) International transmission of stock movements. J Financ Quant Anal 24(2):241-256

Evans T (2006) Efficiency tests of the UK financial futures markets and the impact of electronic trading systems. Appl Financ Econ 16(17):12731283

Fama EF (1965) Capital markets: a review of theory and empirical work. J Financ 25(2):383-417

Fama EF (1970) Efficient capital markets: a review of theory and empirical work. J Financ 25:383-417

Fama EF (1991) Efficient capital markets: II. J

Financ 46:1575-1617

Fama EF (1998) Market efficiency, long-term returns and behavioral finance. J Financ Econ 49:283306

Fama EF, Blume M (1966) Filter rules and stock market trading profits. J Bus 39:226-241

Godfrey MD, Granger CWJ, Morgenstern O (1964) The random walk hypothesis of stock market behaviour. Kyklos 17(1):1-30. doi:10.1111/j.1467-6435.1964.tb02458.x

Granger CWJ (1969) Investigating causal relations by econo-metric models and cross-spectral methods. Econometrica 37(3):424-438 
Granger CWJ (1980) Testing for causality: a personal view-point. J Econ Dyn Control 2:329-352

Greene WH (2003) Econometric analysis, dorling Kindersley (India) Pvt. Ltd., Pearson Education in South Asia: Delhi

Grossman SJ, Stiglitz JE (1980) On the impossibility of informationally efficient markets. Am Econ Rev 70:393-408

Gu AY, Finnerty J (2002) The evolution of market efficiency:

103 years daily data of Dow. Rev Quant Financ Acc 18(3):219-237

Hirayama K, Tsutsui Y (2013) International stock price co-movement. Asian Econ Pap 12(3):157191. doi:10.1162/ ASEP_a_00242

Ito M, Sugiyama S (2009) Measuring the degree of time varying market inefficiency. Econ Lett 103(1):62-64

Ito M, Noda A, Wada T (2012) International stock market efficiency: a non-bayesian time-varying model approach. Appl Econ 46:2744-2754. doi:10.1080/00036846.2014. 909579

Ito M, Noda A, Wada T (2014) International stock market efficiency: a non-bayesian time-varying model approach. Appl Econ 46(23):2744-2754. doi:10.1080/00036846. 2014.909579

Jensen M, Benington G (1970) Random walks and technical theories, some additional evidence. J Financ 25:469-482

Karim B, Karim Z (2012) Integration of ASEAN-5 stock mar-kets: a revisit. Asian Acad of Manag J Account Financ 8(2):21-41

Kim JH, Shamsuddin A, Lim K-P (2011) Stock return predict-ability and the Adaptive markets hypothesis: evidence from century-long U.S. data. J Empir Financ 18:868-879

Lagoarde-Segot T (2009) Financial reforms and timevarying micro-structures in emerging equity markets. J Bank Financ 33(10):1755-1769

Lee (2000) Market efficiency and accounting research: a dis-cussion of capital market research in accounting' by S.P. Kothari. J Account Econ 31:233-253

Lim KP (2008) Sectoral efficiency of the Malaysian stock market and the impact of the Asian financial crisis. Stud Econ Financ 25(3):196-208

Lim K-P, Brooks RD, Kim JH (2007) Financial crisis and stock market efficiency: empirical evidence from Asian coun-tries. Int Rev Financ Anal 17(3):571-591

Lo A (2004) The adaptive markets hypothesis: market efficiency from an evolutionary perspective. J Portf Manag 30:15-29

Lo AW (2005) Reconciling efficient markets with behavioral finance: the adaptive markets hypothesis. J Invest Consult
$7: 21-44$

Lütkepohl H (1991) Introduction to multiple time series ana-lysis. Springer, New York

Mathur I, Subrahmanyam V (1990) Interdependencies among the Nordic and US stock markets. Scand J Econ 92:587-597

Cheung W, Fung S, Tsai S-C (2009) Global capital market interdependence and spillover effect of credit risk: evidence from the 2007-2009 global financial crisis. Appl Financ Econ 20:85-103. doi:10.1080/09603100903262962

Mishra MMPK, Mishra S, Pradhan BB and Mishra SK (2010) Performance of Indian capital market —an empirical ana-lysis. Eur J Econ Financ Adm Sci (23). ISSN 1450-2275

Neely C (2003) Risk-adjusted, ex-ante, optimal technical trading rules in equity markets. Int Rev Econ Financ 12(V0 1):69-87

Ramirez JA, Rodriguez E, Jesus A (2011) A multiscale entropy approach for market efficiency. Int Rev Financ Anal 21:64-69

Rubinstein M (2001) Rational markets: yes or no? The affir-mative case. Financ Anal J 57(3):15-29

Samuelson PA (1965) Proof that properly anticipated prices fluctuate randomly. Ind Manag Rev 6(2):41-49

Saxena S, Villar A (2008) Hedging instruments in emerging market economies. Bank for International Settlements (Financial globalization and emerging market capital flows), Papers No 44

Shleifer A (2000) Inefficient markets: an introduction to behavioural finance, clarendon lectures in economics. Oxford University Press, Oxford, UKSims C (1972) Money, income and causality. Am Econ Rev 62:540-552

Sims C (1980) Macro-economics and reality. Econometrica 48(1):1-48

Tella SA, Yinusa OG, Olusola AT (2011) Global economic crisis and stock markets efficiency: evidence from selected Africa countries. Bogazici J Econ Adm Sci 25(1):139-169

Thaler RH (2000) From homo economicus to homo sapiens.

J Econ Perspect 14(1):133-141

Todea A, Lazar D (2012) Global crisis and relative efficiency: empirical evidence from central and eastern European stock markets. Rev Financ Bank 4(1):45-53

Tsutsui Y, Hirayama K (2004) Appropriate lag specification for daily responses of international stock markets. Appl Financ Econ 14:1017-1025

Wolff CCP (2000) Forward foreign exchange rates and expected future spot rates. Appl Financ Econ 10:371-377 